\title{
Enterovirus Replication Organelles and Inhibitors of Their Formation
}

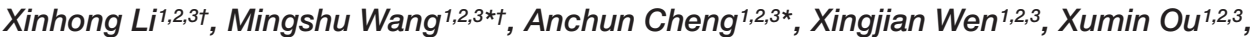 \\ Sai Mao ${ }^{1,2,3}$, Qun Gao ${ }^{1,2,3}$, Di Sun 1,2,3, Renyong Jia ${ }^{1,2,3}$, Qiao Yang ${ }^{1,2,3}$, Ying Wu1,2,3,

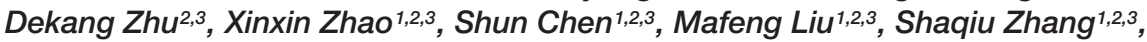 \\ Yunya Liu ${ }^{1,2,3}$, Yanling Yu ${ }^{1,2,3}$, Ling Zhang ${ }^{1,2,3}$, Bin Tian ${ }^{1,3}$, Leichang Pan ${ }^{1,3}$ and \\ Xiaoyue Chen $1,2,3$ \\ ${ }^{1}$ Institute of Preventive Veterinary Medicine, Sichuan Agricultural University, Chengdu, China, ${ }^{2}$ Key Laboratory of Animal \\ Disease and Human Health of Sichuan Province, Sichuan Agricultural University, Chengdu, China, ${ }^{3}$ Avian Disease Research \\ Center, College of Veterinary Medicine, Sichuan Agricultural University, Chengdu, China
}

OPEN ACCESS

Edited by:

Hirokazu Kimura,

Gunma Paz University, Japan

Reviewed by:

Cristina Risco,

National Center for Biotechnology (CNB), Spain

Volker Lohmann,

Heidelberg University Hospital,

Germany

${ }^{*}$ Correspondence:

Mingshu Wang

mshwang@163.com

Anchun Cheng

chenganchun@vip.163.com

tThese authors have contributed equally to this work and share first

authorship

Specialty section:

This article was submitted to

Virology,

a section of the journal

Frontiers in Microbiology

Received: 17 May 2020

Accepted: 10 July 2020

Published: 20 August 2020

Citation:

Li X, Wang M, Cheng A, Wen X, Ou X, Mao S, Gao $Q$, Sun D, Jia R, Yang $Q$, Wu Y, Zhu D, Zhao X, Chen S, Liu M, Zhang S, Liu Y, Yu Y, Zhang L, Tian B, Pan L and Chen $X$ (2020) Enterovirus Replication

Organelles and Inhibitors of Their Formation. Front. Microbiol. 11:1817.

doi: 10.3389/fmicb.2020.01817
Enteroviral replication reorganizes the cellular membrane. Upon infection, viral proteins and hijacked host factors generate unique structures called replication organelles $(R O s)$ to replicate their viral genomes. ROs promote efficient viral genome replication, coordinate the steps of the viral replication cycle, and protect viral RNA from host immune responses. More recent researches have focused on the ultrastructure structures, formation mechanism, and functions in the virus life cycle of ROs. Dynamic model of enterovirus ROs structure is proposed, and the secretory pathway, the autophagy pathway, and lipid metabolism are found to be associated in the formation of ROs. With deeper understanding of ROs, some compounds have been found to show inhibitory effects on viral replication by targeting key proteins in the process of ROs formation. Here, we review the recent findings concerning the role, morphology, biogenesis, formation mechanism, and inhibitors of enterovirus ROs.

Keywords: enteroviruses, replication organelles, biogenesis, lipid metabolism, inhibitors

\section{INTRODUCTION}

Enteroviruses, members of the Picornaviridae family Enterovirus genus, include poliovirus $(\mathrm{PV})$, enterovirus (EV), coxsackievirus (CV), and human rhinovirus (HRV), which can cause poliomyelitis, meningitis, hand-foot-and-mouth disease, respiratory disease, and so on (Tapparel et al., 2013). Enteroviruses are non-enveloped particles, the capsid is a symmetric icosahedral capsid, and the genome is non-segmented single-stranded positive-strand RNA (about $7.5 \mathrm{~kb}$ ). From the $5^{\prime}$ end, the first element of the genome is VPg (3B), which is connected to the genome by covalent bond. After the VPg is the 5'non-translated region (NTR), where the "cloverleaf" and the internal ribosome entry site (IRES) are. This is followed by a single large open reading frame (ORF). The 3'end is a short 3'NTR, containing a poly (A) tail (Jiang et al., 2014; Peersen, 2017). The ORF encodes a polyprotein, about 2,300 amino acids. It is artificially separated into three sections, P1, P2, and P3. P1 encodes structural proteins, which are related to the assembly of viral capsids. P2 and P3 encode non-structural proteins and participate in virus replication and virus-host interaction (Belov et al., 2012; Cao et al., 2012; Wen et al., 2015).

Positive-strand RNA viruses from different families (such as Picornaviridae, Flaviviridae, Coronaviridae, and Togaviridae) rely on host cell machinery to replicate their genome and generate progeny viral particles. Upon infection, virus induce the rearrangements of cellular membranes 
to form specific intracellular compartment called virus factory or viroplasma, which contain unique platforms known as replication organelles (ROs) to replicate viral RNA (vRNA). Virus replication complexes include viral proteins needed for viral replication and coopted host factors, which constitute ROs with the sites of virus particle assemble (Novoa et al., 2005; Owino and Chu, 2019; Sachse et al., 2019). Like all positivestrand RNA viruses, enterovirus infection causes the cellular membranes modified to produce ROs for replication of vRNA. After years of efforts by scientists, the morphology, biogenesis, and related pathways of ROs biogenesis (including the secretory pathway, autophagy, and lipid metabolism) are discovered. In addition, finding potential targets for antiviral therapies during the ROs formation process is a very active field of research. In this review, we outline the research progress about the role, morphology, and biogenesis of enterovirus ROs, and briefly describe inhibitors that target ROs formation. It improves our understanding of enterovirus replication and provides reference for the development of anti-enterovirus drugs.

\section{FUNCTION OF RO}

It is theorized that ROs promote virus replication by raising the concentrations of proteins involved in virus replication, providing platform to assemble multisubunit ROs, and effectively coordinating the different steps of the replication process to improve replication efficiency (McCloskey and Poo, 1986; Ravindran et al., 2016). The membrane lipids on the ROs can regulate virus polyprotein processing and enzyme activity. For example, cholesterol on ROs is vital for regulating the processing kinetics of viral 3CD pro (Ilnytska et al., 2013). ROs also help viruses evade innate immunity by hiding double-stranded RNA (dsRNA), a replication intermediate of vRNA, from cellular sensors (den Boon and Ahlquist, 2010; Belov et al., 2012; Viktorova et al., 2018). In the case of PV, membranous scaffold of the ROs is essential to protect vRNA from innate immunity, especially in multicycle replication conditions (Viktorova et al., 2018). However, innate immunity do not increase when CVB3 ROs generation is delayed, suggesting that ROs are not indispensable for innate immune evasion (Melia et al., 2017).

\section{THE MORPHOLOGY AND BIOGENESIS OF RO}

Although the RO structures induced by different viruses have their own unique characteristics, their structures are very similar, suggesting that viruses have adopted a conserved mechanism to assemble ROs during long-term evolution (Zhang et al., 2015). There are two forms of ROs. The cell membrane of the ER or other donor organelles recess inward, forming a concealed structure containing all the elements necessary for replication (formed by negative curved membranes), which is adopted by dengue virus, Zika virus, and so on. Other viruses (hepatitis $\mathrm{C}$ virus, picornaviruses, arterivirus, and coronavirus) produce double-membrane vesicles (DMVs), which are formed by squeezing the donor membrane (formed by positive curved membranes). Enteroviruses induce membrane rearrangement by the second way (Bienz et al., 1992; Paul and Bartenschlager, 2013; Roulin et al., 2014; Blanchard and Roingeard, 2015; Ertel et al., 2017; Strating and van Kuppeveld, 2017). Viral proteins participate in the formation of ROs. PV $2 \mathrm{BC}$ and $3 \mathrm{~A}$ proteins cause ER change, triggering the arising of ROs (Suhy et al., 2000). EV71 2C protein interacts with reticulon 3 (RTN3), which can change the curvature of the ER membrane (Tang et al., 2007).

For a long time, in the studies using two-dimensional electron microscopy, enterovirus ROs were regarded as vesicles with single or double membranes (Kallman et al., 1958; Bienz et al., 1980; Egger et al., 1996; Paul and Bartenschlager, 2013; RomeroBrey and Bartenschlager, 2014). In recent years, the threedimensional structure of enteroviral ROs has been revealed. During infection, the structures of ROs are constantly changing, indicating that ROs are dynamic. They seem to evolve from each other with the process of viral infection. In early infection, enteroviruses ROs appear in cytoplasm with the form of singlemembrane tubules (SMTs). With the progress of infection, SMTs transform into DMVs via membrane pairing and fission. In the late stage of infection, multilamellar vesicles (MVs) appear in the cytoplasm. The formation of DMVs and MVs is via membrane apposition, enwrapping, and fusion (Limpens et al., 2011; Belov et al., 2012; van der Schaar et al., 2016b; Oh et al., 2018; Wolff et al., 2020). DMVs are enwrapped by one or multiple cisternae to form MVs (Limpens et al., 2011). The membrane structures formed after enterovirus infection are discontinuous, and SMT and DMV are independent, separate structures (Figure 1). Enterovirus ROs are different from ROs of encephalomyocarditis virus, equine arteritis virus, and severe acute respiratory syndrome (SARS) coronavirus, which induce interconnected DMVs to comprise reticulovesicular networks (Knoops et al., 2008, 2012; Melia et al., 2018). Enterovirus ROs apparently lack of pores which let the vRNA enter ROs inside, suggesting vRNA replication takes place on the enterovirus ROs cytoplasmic leaflet (Limpens et al., 2011; Belov et al., 2012; Strating and van Kuppeveld, 2017).

Do the three structures (SMTs, DMVs, and MVs) all participate in genome replication? Researches on PV and CVB3 infection elucidated that there is a link between viral proteins, dsRNA, and both SMTs and DMVs. In the exponential phase of vRNA replication, the structure of ROs mainly forms SMTs, suggesting that the early and mid-term SMTs are related to the onset and most dense rates of RNA synthesis. DMVs appear in large numbers after the most active stage of vRNA synthesis, indicating that DMVs may contribute to other steps of viral life cycle, such as virus assembly (Limpens et al., 2011; Belov et al., 2012; Oh et al., 2018). This is different from HCV that DMVs of HCV is the place vRNA replication take place (Lee et al., 2019). DMVs of PV are postulated to mediate non-lytic release of progeny virus particles (Kirkegaard and Jackson, 2005; Chen et al., 2015). DMVs of SARS-coronavirus are suggested to conceal vRNA to escape the antiviral response triggered by dsRNA (Knoops et al., 2008).

Previous studies have shown that enteroviruses form ROs that are juxtaposed with exit sites of the ER, where viruses anchor 

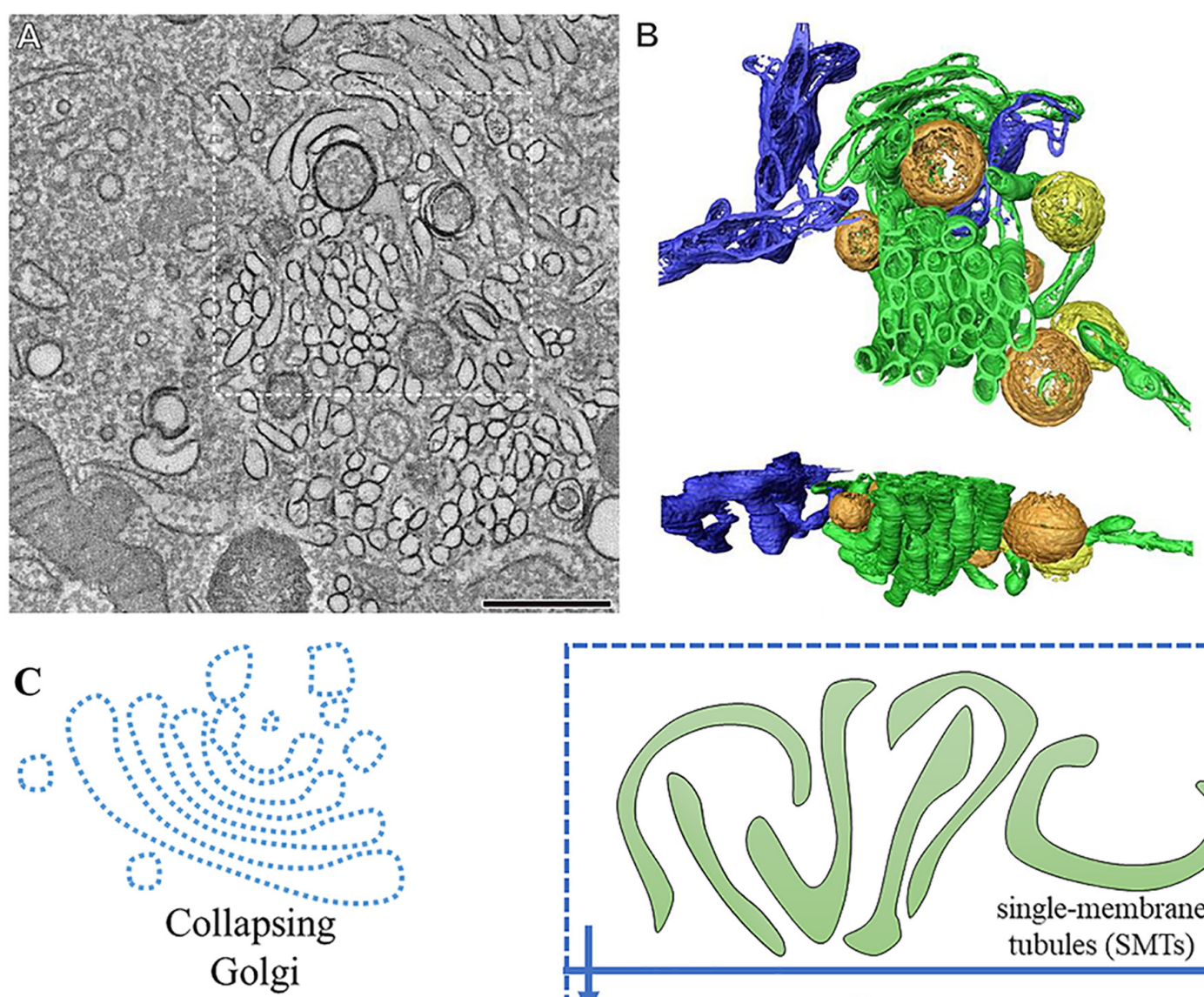

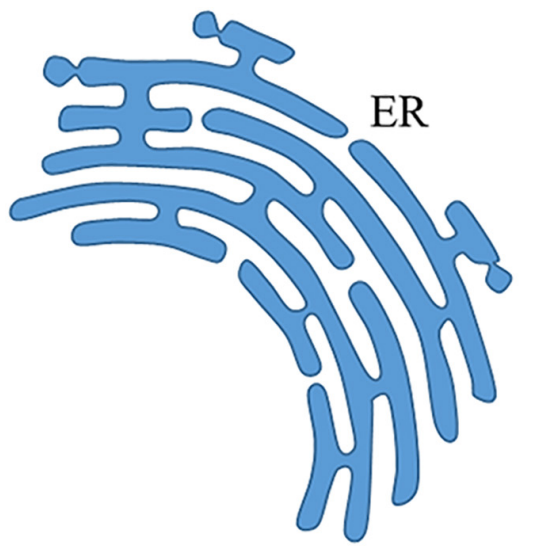

Donor organelles

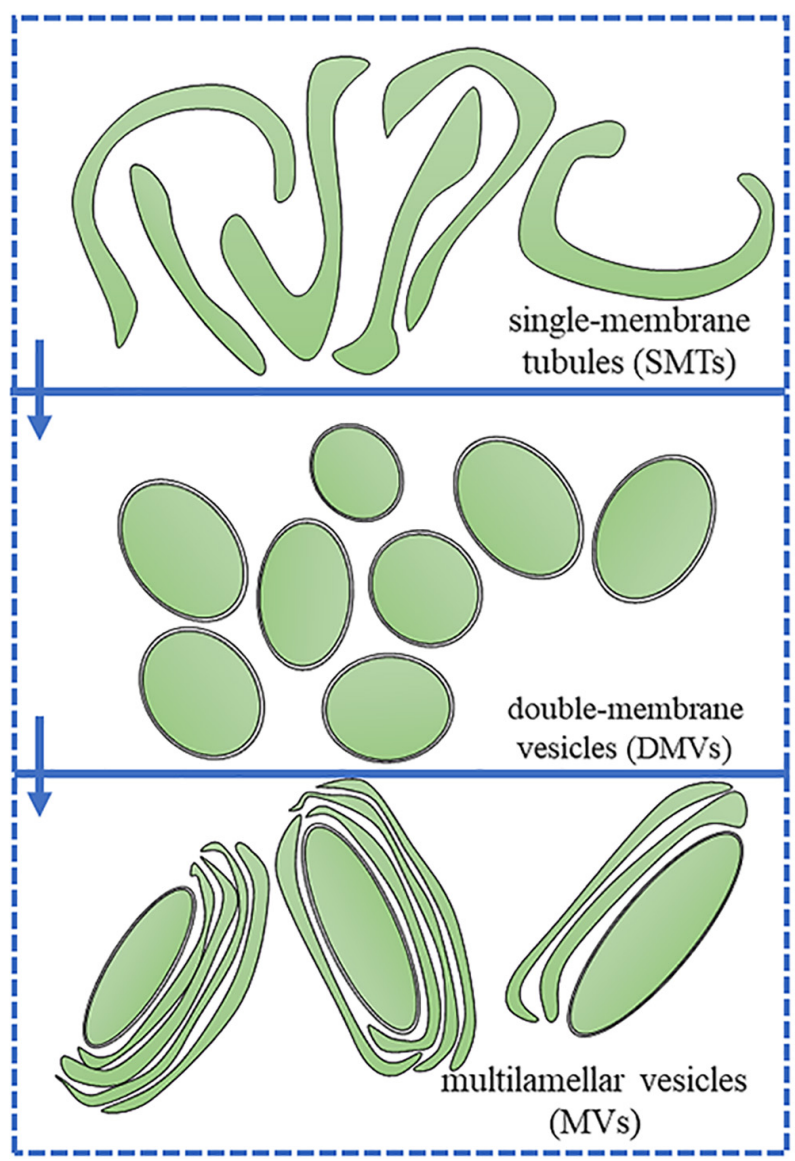

Enterovirus ROs

FIGURE 1 | The morphology of enterovirus ROs. (A) Tomographic slice through the serial tomogram of a CVB3-infected cell at 5 h post-infection, with clusters of SMT and sparsely embedded DMVs. Scale bar is $500 \mathrm{~nm}$. (B) Top and side views of a surface-rendered model of the region boxed in panel (A) showing SMT (green), open DMVs (orange), closed DMVs (yellow), and ER (blue). (C) Pattern about of RO morphology. Enterovirus ROs are generated from the ER and the Golgi. During the early stages of infection, enteroviruses produce ROs with single-membrane tubule (SMT) morphology. SMTs transform into double-membrane vesicles (DMVs) and multilamellar vesicles (MVs) with the progression of infection. (A,B) Adapted from Limpens et al. (2011). The original images have been published under the Creative Commons Attribution-Non-commercial-Share Alike 3.0 Unported license. We have obtained author's permission. 
the viral replication mechanism (Suhy et al., 2000; Hsu et al., 2010; Limpens et al., 2011). During the process of enteroviral infection, Golgi collapse and cannot be detected, suggesting that the membranes of the ROs may be derived from the Golgi (Hsu et al., 2010; Mousnier et al., 2014; van der Schaar et al., 2016b). The origin of CVB3 ROs was elucidated. Biogenesis of CVB3 ROs was found to occur first at the ER and then at Golgi membranes (Melia et al., 2019). In the early infection, when the level of viral proteins is low, PV and CVB3 make use of the Golgi compartment and trans-Golgi network (TGN) to synthesize vRNA (Hsu et al., 2010; van der Schaar et al., 2016b). The CVB3 3A-H57Y mutant, which can replicate under phosphatidylinositol 4-kinase beta (PI4KB) inhibition and can not form ROs, replicates at the Golgi (Melia et al., 2017).

\section{ROLE OF THE SECRETORY PATHWAY IN RO BIOGENESIS}

Several studies have investigated whether the replication of $\mathrm{PV}$ and CVB3 requires guanine nucleotide exchange factor 1 (GBF1), a guanine nucleotide exchange factor (GEF) of ADP ribosylation factor (Arf), involved in the secretory pathway. GBF1 recycles Arf from GDP-bound form to GTP-bound form (Belov et al., 2007a; Lanke et al., 2009). The replication of EV71 and PV depends on GBF1-mediated activation of Arf (Wang et al., 2014; Viktorova et al., 2019). Upon CVB3 infection, newly synthesized proteins, such as $3 \mathrm{~A}$ protein, are located on secretory organelle membranes and recruit effector through GBF1/Arf1, thereby enhancing the accumulation of PI4KB over Coat protein complex I (COPI), causing the producing of uncoated phosphatidylinositol 4-phosphate (PI4P)-enriched structures adjacent to ER exit sites (Hsu et al., 2010). PV requires a little subset of normal GBF1 functions. GBF1 components are crucial to support virus replication under different situations. 3A-GBF1 interaction and membrane targeting function are mediated by the GBF1 C-terminal domain, which are vital to recruiting GBF1 to ROs. If either is damaged, functional ROs are still formed, but when both are inactivated, no RO is formed (Viktorova et al., 2019). Viral protein 3CD has also been demonstrated to be related to the GBF1, Arf1, and PI4KB pathways (Belov et al., 2007b; Banerjee et al., 2018). Other GEFs (BIG1 and BIG2) are also involved in the replication of enteroviruses. After $\mathrm{PV}$ infection, viral $3 \mathrm{CD}$ protein promotes the binding of Arf to the membrane by recruiting BIG1 and BIG2, which is linked to the ROs formation (Belov et al., 2007a,b).

COPI and Coat protein complex II (COPII) vesicles are important part of the transport between ER and Golgi. COPI vesicles assume the role of transporting goods to Golgi, limiting lipid storage and maintaining lipid homeostasis. COPII act a vital role in the transport of proteins and lipids from ER to Golgi (Lee et al., 2004; Beller et al., 2008). COPI and COPII both are involved in the formation of enterovirus RO. Brefeldin A (BFA), an inhibitor that targets COPI, shows a strong inhibitory action on the vRNA replication of PV. EV11, CVA-21, and CVB3 replication is also inhibited by $\mathrm{BFA}$, indicating that COPI vesicle trafficking is instrumental to the replication of enteroviruses
(Irurzun et al., 1992; Maynell et al., 1992; Gazina et al., 2002; van der Linden et al., 2010). Replication of EV-A71 requires COPI, which may be recruited to ROs through the interaction of the COPI coatomer and $2 \mathrm{C}$ protein of EV-A71 (Wang et al., 2012). The generation of PV ROs is associated in cellular COPII germination mechanism (Rust et al., 2001; Trahey et al., 2012).

UDP-glucose glycoprotein glucosyltransferase 1 (UGGT1) is a crucial protein in ER involved in the unfolded protein response (UPR). UGGT1 and EV-A71 3D polymerase (3D ${ }^{\mathrm{pol}}$ ) coprecipitate with other factors related to ROs to encourage EV-A71 replication (Huang et al., 2017; Table 1).

\section{ROLE OF AUTOPHAGY IN RO BIOGENESIS}

Autophagy is a highly conservative lysosomal pathway unique to eukaryotic cells that degrades misfolded or redundant proteins in cells, damaged organelles, and intracellular pathogens. Autophagy is initiated by the generation of crescent isolation membrane vesicles called isolation membranes or phagophores. Subsequently, phagophores grow and fuse to form closed double-layer membrane autophagosomes. After elongation, autophagosomes have two directions. One is to form autolysosomes by fusing with lysosomes. The other is to fuse with late endosomes first to generate amphiphiles, and then fuse with lysosomes to produce autolysosomes (Lai et al., 2016; Pleet et al., 2018; Sun et al., 2019).

Multiple studies have reported that enteroviruses can induce and exploit autophagy to support the replication of virus. Studies find that the vesicles formed after enterovirus infection showed the features of autophagosomes, for example, the double-layer membrane structure of vesicles, the increase of esterified LC3, and the enrichment of cells with LC3 punctate location (Taylor and Kirkegaard, 2007; Wong et al., 2008; Yoon et al., 2008; Klein and Jackson, 2011; Alirezaei et al., 2012; Shi et al., 2015). Viral components of ROs (2B, 2BC, $3 A$, and $3 A B)$ can trigger generation of esterified LC3 and/or double-membraned liposomes (Suhy et al., 2000; Wang et al., 2013; Wu et al., 2016; Lai et al., 2017). Induction of autophagy by rapamycin and nutrient deprivation leads to an increase in enteroviral replication. Contrary to the inhibition of autophagosomes formation by 3-methyladenine (3-MA), which can inhibit the formation of autophagosomes by inhibiting the activation of type III PI-3 kinase, and knockdown/knockout the genes vital for autophagosomes formation (ATG5, ATG7, ATG9, Beclin1, VPS34, LC3, ULK1, and FIP2000) significantly reduced enterovirus replication (Sugden et al., 2005; Wong et al., 2008; Alirezaei et al., 2012; Abernathy et al., 2019). Using an antibody against dsRNA, dsRNA was found to colocalize with LC3 in late-infection of PV (Richards et al., 2014). The above results indicate that autophagy can promote virus replication and that autophagy may be involved in the ROs generation. Enteroviruses may use the autophagy pathway to provide membranous scaffolds for ROs generation after infection. CVB3 infection cause inhibition of the fusion of autophagosomes and lysosomes/late 
TABLE 1 | The host proteins associated with RO biogenesis.

\begin{tabular}{|c|c|c|c|}
\hline Host protein & Virus (related viral protein) & Function in RO biogenesis & References \\
\hline GBF1/Arf1 & EV71 PV(3CD) CVB3(3A) & $\begin{array}{l}\text { Cooperate viral } 3 \mathrm{~A} \text { to recruit } \mathrm{PI} 4 \mathrm{~KB} \text { or participate in } \mathrm{ROs} \\
\text { formation }\end{array}$ & Belov et al., 2007b; Hsu et al., 2010 \\
\hline BIG1 BIG2 & $P V(3 C D)$ & Linked to the ROs formation & Belov et al., 2007a,b \\
\hline COPI & $\begin{array}{l}\text { PV EV11 CVA-21 CVB3 } \\
\text { EV-A71(2C) }\end{array}$ & Related to ROs formation & $\begin{array}{l}\text { Maynell et al., 1992; Gazina et al., } \\
\text { 2002; van der Linden et al., } 2010\end{array}$ \\
\hline COPII & PV & COPII germination mechanism is related to ROs formation & Rust et al., 2001 \\
\hline UGGT1 & EV-A71(3D) & $\begin{array}{l}\text { UGGT1 and 3D }{ }^{\text {pol }} \text { coprecipitate with other factors related to } \\
\text { ROs to encourage EVA71 replication }\end{array}$ & Huang et al., 2017 \\
\hline SNAP29 & CVB3(3C) EV-D68(3C) & $\begin{array}{l}\text { Promote autophagosomes accumulation to provide additional } \\
\text { membrane scaffolds for ROs generation }\end{array}$ & Mohamud et al., 2018 \\
\hline PLEKHM1 & CVB3(3C) & & \\
\hline BPIFB3 & CVB & Related to ROs morphology & Delorme-Axford et al., 2014 \\
\hline FASN & PV CVB3 & Synthesize FAs on ROs to synthesize PC & Rassmann et al., 2007 \\
\hline ACSL3 & $P V(2 A)$ & $\begin{array}{l}\text { Induce increased import of FAs in infected cells and } \\
\text { up-regulation of phospholipid synthesis }\end{array}$ & Nchoutmboube et al., 2013 \\
\hline $\mathrm{CCT} \alpha$ & $P V(2 A)$ & Bind to the ROs membrane to synthesize PC & Viktorova et al., 2018 \\
\hline ACBD3 & Enterovirus(3A) & Cooperate viral $3 \mathrm{~A}$ to recruit PI4KB & $\begin{array}{l}\text { Greninger et al., 2012; Lei et al., } \\
\text { 2017; Lyoo et al., } 2019\end{array}$ \\
\hline PI4KB & Enterovirus(3A) & Phosphorylate PI to PI4P & $\begin{array}{l}\text { Hsu et al., 2010; Spickler et al., } \\
\text { 2013; Roulin et al., } 2014\end{array}$ \\
\hline c10orf76 & CVA10 PV & $\begin{array}{l}\text { Contribute to proper Arf1 activation and increases the PI4P } \\
\text { level of ROs }\end{array}$ & $\begin{array}{l}\text { McPhail et al., 2020; Voilquin et al., } \\
2020\end{array}$ \\
\hline HSL & HRV-A16 & $\begin{array}{l}\text { Hydrolyze cholesterol-ester stored in LDs to increase the } \\
\text { cholesterol content of ROs }\end{array}$ & Roulin et al., 2014 \\
\hline OSBPL & HRV-A1A & Increase RO cholesterol content & Roulin et al., 2014 \\
\hline Rab11 & PV(2BC) CVB3(2BC) & $\begin{array}{l}\text { Related to transporting cholesterol to ROs and preventing } \\
\text { cholesterol back to the PM }\end{array}$ & $\begin{array}{l}\text { Hsu et al., 2010; Ilnytska et al., } \\
2013\end{array}$ \\
\hline OSBP & HRV PV CVB3 & $\begin{array}{l}\text { Drive PI4P-cholesterol countercurrents to increase the level of } \\
\text { cholesterol in ROs }\end{array}$ & Arita, 2014; Roulin et al., 2014 \\
\hline
\end{tabular}

endosomes through CVB3 proteinase 3C cleave synaptosomalassociated protein 29 (SNAP29) and pleckstrin homology domain containing protein family member 1 (PLEKHM1), two vital proteins related to the autophagosomes fusion. This promotes autophagosomes accumulation to provide additional membrane scaffolds for ROs generation (Mohamud et al., 2018). SNAP29 was also found to be cleaved after EV-D68 infection (Corona et al., 2018). Bactericidal/permeability-increasing protein (BPI) fold-containing family $\mathrm{B}$, member 3 (BPIFB3) was identified to be involved in $\mathrm{CVB}$ infection for it negatively regulated non-canonical form of autophagy. After silencing BPIFB3, CVB replication increased and CVB induced ROs morphology changed dramatically (Delorme-Axford et al., 2014; Table 1).

Other studies have shown that the autophagy pathway is associated with other aspects of the enterovirus life cycle, including entry, genome package, assembly, maturation, and release (Richards and Jackson, 2012; Chiramel et al., 2013; Mohamud and Luo, 2019).

\section{LIPID METABOLISM OF RO BIOGENESIS}

The membrane is mainly composed of 5 kinds of phospholipids: phosphatidylcholine (PC), phosphatidylethanolamine (PE), phosphatidylserine (PS), phosphatidylinositol (PI), and sphingomyelin (SM) (Spector and Yorek, 1985). Phospholipids are amphiphilic and are divided into hydrophilic groups (head) and hydrophobic groups (tail) (De Craene et al., 2017). The head group is the main determinant of lipid properties (charge, shape, and interaction with proteins), and changes in fatty acids (FAs) length and saturation that make up the hydrophobic part of phospholipids also affect membrane properties (such as lipid accumulation and fluidity) (van Meer et al., 2008). Sterols are essential elements of membrane lipids and participate in regulating membrane fluidity, stability, and permeability. Cholesterol is the main sterol in mammalian cell membranes (De Craene et al., 2017). Compared with the organelle membrane in uninfected cells, the composition of enterovirus ROs is special. The ROs membrane is rich in PI4P, PC, and cholesterol (Ilnytska et al., 2013; Nchoutmboube et al., 2015; Altan-Bonnet, 2017).

\section{PC}

During PV infection, the level of PC, the most common glycerophospholipid, increases (Vance et al., 1980; Zhang et al., 2016). The enrichment of PC with short palmitoylation likely produces more fluid membranes with intrinsic ability, thus forming convoluted tubular matrix of ROs (Belov, 2014).

To accumulate PC at ROs, it is vital to accumulate FAs to synthesize PC. One way is to recruit fatty acid synthase (FASN) to the ROs (Rassmann et al., 2007; Belov and van Kuppeveld, 
2012). As the de novo synthesis pathway of FAs is needed, treatment with phospholipid synthesis inhibitors greatly reduced the replication and infectivity of PV and CVB3 (Guinea and Carrasco, 1990; Molla et al., 1993; Rassmann et al., 2007; Wilsky et al., 2012). Another way is to uptake FAs from extracellular medium (Nchoutmboube et al., 2013; Belov, 2014). Infection with PV activated the import of long-chain FAs, which related to the upregulation of cellular long-chain acyl-CoA synthetase long-chain family member 3 (ACSL3) activity. Viral protein 2A was required in this process independent of its protease activity. Imported FAs were converted into hydrophilic acyl-CoAs and synthesize triglycerides (TGs) stored in lipid droplets (LDs) in uninfected cells, while all newly imported FAs were used for PC biosynthesis in virus-infected cells (Nchoutmboube et al., 2013). However, a recent paper pointed out that upon PV infection, FAs taken from extracellular medium were not directly used for PC synthesis but were used to generate TGs stored in LDs (Laufman et al., 2019). Lipophagy and lipolysis are two ways to mobilize LD lipid. The lipids in LDs are transported to lysosomes by autophagy, called lipophagy. Lipases are recruited to LD surface to sequential hydrolysis of TGs stored within LDs, called Lipolysis (Zechner et al., 2017). After enterovirus infection, TGs within LDs transformed to FAs through lipolytic. Free FA was used to synthesize PC for ROs generation (Belov and van Kuppeveld, 2019; Laufman et al., 2019). PV infection induced massive translocation of CTP-phosphocholine-cytidyl transferase alpha (CCT $\alpha)$, the key enzyme in PC synthesis. CCT $\alpha$ transferred from the nuclei to the cytoplasm and this process was related to the protease activity of the $2 \mathrm{~A}$ protein. CCT $\alpha$ bound to the ROs membrane to synthesize PC (Viktorova et al., 2018; Table 1; Figure 2).

\section{PI}

Although PI accounts for only a small part of the total amount of phospholipids, it is the main determinant of organelle characteristics and functions. The most abundant PI in human cells is PI4P, which accounts for approximately $45 \%$ of the total intracellular PI. PI4P regulates membrane transport and metabolism by regulating the recruitment of host factors involved in lipid transfer (Payrastre et al., 2001; van der Schaar et al., 2016a; De Craene et al., 2017). PI4P is found to be related to enterovirus replication, such as PV, CVB3, HRV, and echovirus (Hsu et al., 2010; Altan-Bonnet and Balla, 2012; Ilnytska et al., 2013; Roulin et al., 2014). In mammalian cells, there are four enzymes that can phosphorylate PI to PI4P: phosphatidylinositol 4-kinase type 2 alpha (PI4K2A), phosphatidylinositol 4-kinase type 2 beta (PI4K2B), phosphatidylinositol 4-kinase alpha (PI4KA), and PI4KB (Delang et al., 2012; Dornan et al., 2016; Viaud et al., 2016; Burke, 2018). Upon enterovirus infection, ROs relied on PI4KB to phosphorylate PI to PI4P, creating a PI4P-enriched environment (Hsu et al., 2010; Spickler et al., 2013; Roulin et al., 2014). PI4P is suggested to be involved in the RNA polymerase complex and other host proteins involved in vRNA replication recruitment and stabilization on ROs membranes to promote the synthesis of vRNA (Hsu et al., 2010; Altan-Bonnet, 2017; Melia et al., 2017). In addition, it is involved in cellular lipid rearrangement, especially by recruiting oxysterol binding protein (OSBP) to transport cholesterol to ROs (Arita, 2014; Roulin et al., 2014).

Previous studies have demonstrated that enteroviral protein $3 \mathrm{~A}$ can recruit and activate $\mathrm{PI} 4 \mathrm{~KB}$. Although the $3 \mathrm{~A}$ protein can coprecipitate with $\mathrm{PI} 4 \mathrm{~KB}$, it does not show a direct interaction, indicating that the viral $3 \mathrm{~A}$ protein recruits $\mathrm{PI} 4 \mathrm{~KB}$ through indirect interaction (Dorobantu et al., 2014). Thus far, two host factors have been found to participate in this process. One is GBF1. The viral 3A protein binds and regulates GBF1/Arf1 to increase the accumulation of PI4KB on ROs which catalyzes the production of PI4P (Hsu et al., 2010; Sasvari and Nagy, 2010). The second is the Golgi resident protein acyl-CoA-binding domain-containing 3 (ACBD3), also referred to as GCP60 and PAP7 (Greninger et al., 2012; Lei et al., 2017; Lyoo et al., 2019; Yue et al., 2019). ACBD3 is composed of an acyl-CoA binding (ACB) domain, a charged-amino-acid region (CAR), a glutamine-rich (Q) domain, and a Golgi dynamics (GOLD) domain (Yue et al., 2019). Enterovirus protein 3A binds to ACBD3 and then recruits PI4KB to ROs, where PI4KB produces a PI4P-enriched environment (Sasaki et al., 2012; Teoule et al., 2013; Lei et al., 2017; Xiao et al., 2017; Lyoo et al., 2019). The GOLD domain interacts with the enterovirus 3A protein, and the Q domain interacts with PI4KB (Klima et al., 2016; Chalupska et al., 2019). ACBD3 not only is an intermediary regulator of $3 \mathrm{~A}$ and PI4KB but also participates in the correct localization of viral 3A protein (Lyoo et al., 2019). Crystal structures of the enterovirus $3 \mathrm{~A}$ protein and $\mathrm{ACBD} 3$ complex have been characterized. Membrane bound protein $3 \mathrm{~A}$ localizes on the membrane and binds to the GOLD domain of ACBD3 to form 3A-ACBD3 complex. Two 3A-ACBD3 complexes are close to each other, and a hydrophobic core is formed in the area near the four 3A N-terminal alpha helices to form a heterotetramer. The Q domain of ACBD3 binds to the N-terminus of PI4KB to mediate the direct, high-affinity interface between ACBD3 and PI4KB. 3A-ACBD3-PI4KB complex facilitates enterovirus replication (Horova et al., 2019; Smola et al., 2020). However, PI4KB and ACBD3 recruitment by CVB3 and HRV 3A likely independent of GBF1/Arf1 and ACBD3 (Dorobantu et al., 2014, 2015). And recent research about PI4KB using trans complementation with PI4KB mutants in a PI4KB-knockout cell line shows that interaction of PI4KB with host proteins (ACBD3, RAB11A, and 14-3-3) is not essential for EV replication once PI4KB has been expressed and that PI4KB is functionally independent from host proteins regarding EV replication (Arita, 2019). They are different from the above results, which may be due to the use of siRNA to knock down endogenous GBF1 and ACBD3 levels but not cause a complete knock out. Recruiting PI4KB in enterovirus replication requires only a small amount of GBF1/Arf1 and ACBD3 to function in ROs (Lyoo et al., 2019). Interestingly, reducing the content of endogenous ACBD3 by knock down or knock out increases the replication of HRV16, indicating that ACBD3 is a crucial factor in HRV16 replication (Xiao et al., 2017). $\mathrm{PV} 2 \mathrm{BC}$ protein and HRV 2B protein can also recruit PI4KB to RO membranes (Arita, 2014; Roulin et al., 2018).

Recently, c10orf76 (chromosome 10, ORF 76, also known as Armadillo-like helical domain-containing protein 3 [ARMH3]) was identified as a participant of the replication of CV-A10 and 


\section{Extracellular medium}

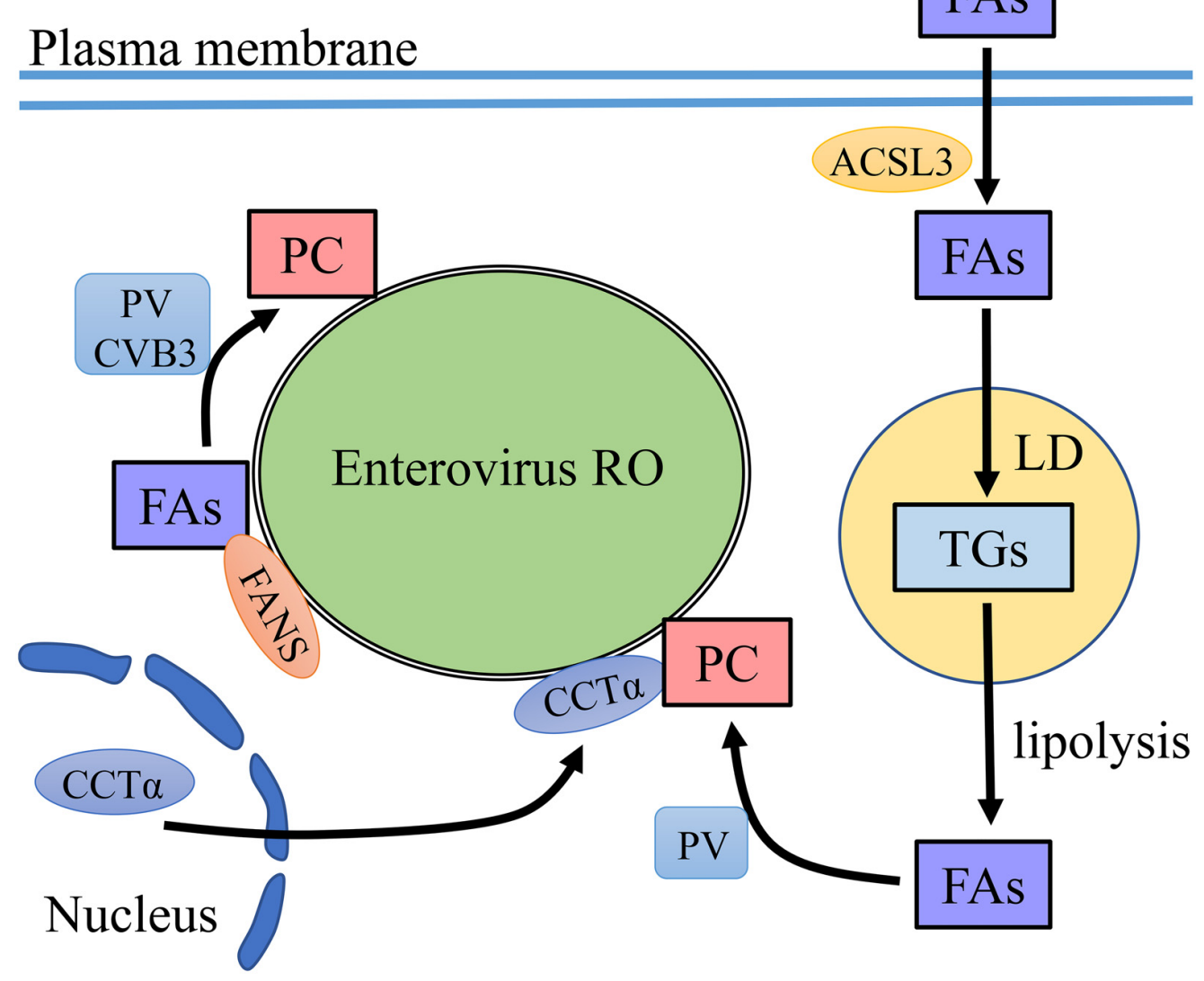

FIGURE 2 | PC recruitment on enterovirus ROs. FAs are precursors for PC synthesis. Enteroviruses increase the level of FAs via two ways. One is to recruit FANS to enterovirus RO to synthesize FAs and then FAs convert to PC on the membrane of ROs. The other is to uptake FAs from the extracellular medium which depends on ACSL3. The imported FAs are targeted to TG synthesis and storage in LDs. FAs are released from LDs by lipolysis. CCTa translocates from the nucleus to the membrane of ROs, where CCT $\alpha$ synthesizes PC using FAs released from LDs.

PV but not CV-B1 (McPhail et al., 2020; Voilquin et al., 2020). $\mathrm{PI} 4 \mathrm{~KB}$ can recruit $\mathrm{c} 10$ orf76 to the 10 orf76-dependent virus ROs membrane via the c10orf76-PI4KB interface. c10orf76 on the ROs may contribute to proper Arf1 activation and increase the PI4P level of ROs (McPhail et al., 2020; Table 1; Figure 3).

\section{Cholesterol}

Cholesterol, intercalated between phospholipid bilayers, is an important component of the cell membrane. It is related to membrane fluidity and curvature (Nchoutmboube et al., 2015). The ROs induced by enteroviruses, such as HRV, CVB3, PV, and echovirus, are enriched in cholesterol. Cholesterol can promote enterovirus replication and regulate the process of proteolysis of polyproteins related to virus replication and package. In addition, it can offset the increased fluidity caused by PI4P (Ilnytska et al., 2013; Arita, 2014; Roulin et al., 2014; Albulescu et al., 2015b). In contrast, echovirus 1 replication is not related to cholesterol (Siljamaki et al., 2013). The reason for the above different results may be due to different research strategies.

There are three ways to improve the content of ER membrane cholesterol. One is de novo biosynthesis. Cholesterol is produced from acetyl-CoA via the mevalonate pathway, and the rate limiting enzyme 3-hydroxy-3-methylglutaryl-CoA reductase (HMGCR) is involved. The second is uptaking extracellular cholesterol through late endosomes. The third way to generate cholesterol by hydrolyzing cholesteryl-ester in LDs or late endosomes (Ikonen, 2008). Replication of enterovirus is not sensitive to the inhibition of HMGCR, indicating that de novo cholesterol synthesis does not participate in enterovirus replication (Roulin et al., 2014; Albulescu et al., 2015b; Luo et al., 2020). HRV-A16 depends on cholesteryl-esterase hormonesensitive lipase (HSL) to hydrolyze cholesterol-ester stored in LDs, as HRV-A16 is sensitive to HSL inhibitors. However, HRVA1A relies on OSBP-like (OSBPL) proteins, like OSBPL9 and OSBPL11 (Roulin et al., 2014). During PV and CVB3 infection, the $2 \mathrm{BC}$ protein activates clathrin-mediated endocytosis (CME) to redistribute cholesterol from the plasma membrane and extracellular medium. Cholesterol entering the cytoplasm is transported into Rab11 recycling endosomes. The viral 3A protein recruit PI4KB, which directly binds Rab11, to harnesses Rab11 recycling endosomes, which transport cholesterol to ROs and prevent cholesterol back to the plasma membrane (Hsu 


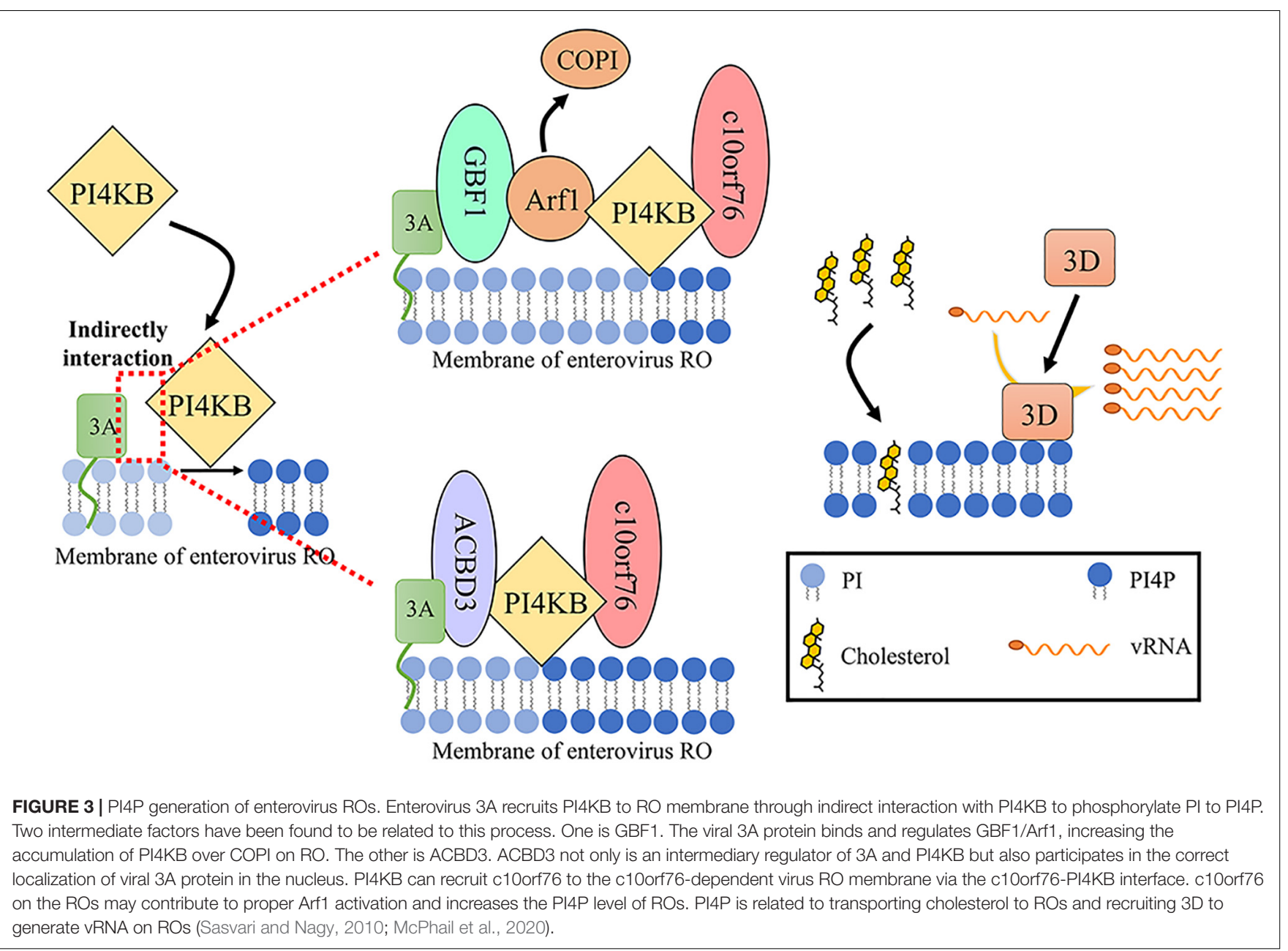

et al., 2010; Ilnytska et al., 2013; Strating et al., 2013). In addition, HRV, PV, and CVB3 are reported to use OSBP and other host factors driving PI4P-cholesterol countercurrents to increase the level of cholesterol in ROs (Arita, 2014; Roulin et al., 2014). OSBP contain an FFAT motif that bind to VAP; an pleckstrin homology $(\mathrm{PH})$ domain to bind PI4P, through which OSBP can connect many organelles; and the OSBPrelated domain (ORD) that binds and transports cholesterol and quickly exchanges cholesterol at membrane contact sites (MCSs) (Mesmin et al., 2017; Ikonen, 2018). After enterovirus infection, OSBP establishes MCSs between the ER and the ROs in order to maintain condition with high cholesterol content in ROs. OSBP mediates the transfer of PI4P from the ROs to the ER while cholesterol transfer from the ER to the ROs (Table 1). Sac1, which converts PI4P to PI on ER membrane, and PI transfer protein beta (PITP-b), which transports PI to the ROs, where PI is phosphorylated by PI4KB to PI4P, are vital for completing the cycle (Mesmin et al., 2013; Roulin et al., 2014; Nchoutmboube et al., 2015; van der Schaar et al., 2016a; Figure 4). Knockdown or pharmacological inhibition of OSBP inhibited the replication of enterovirus (Roulin et al., 2014; Strating et al., 2015). Moreover, after silencing key proteins in PI4P-cholesterol cycle between ER and RO, enterovirus replication were damaged, indicating that the PI4P-cholesterol cycle between ER and RO have important effect on the replication of enterovirus (Hsu et al., 2010; Roulin et al., 2014).

\section{INHIBITORS}

\section{Target PI4KB}

PIK93 is the first discovered specific PI4KB inhibitor. It can inhibit PI4KA at a concentration 100 times higher than that of PI4KB, and it can also inhibit phosphatidylinositol 3-kinase (Knight et al., 2006). PIK93 can inhibit PI4KB to inhibit the interaction of viral $3 \mathrm{D}^{\text {pol }}$ with PI4P on the RO membrane. For the high cross reactivity of PIK93, designing more potent and more selective PI4KB inhibitors is an important field of research (Rutaganira et al., 2016). Enviroxime is found to have potent activity against rhinovirus in 1980 (Wikel et al., 1980). Then it is identified to target PI4KB to against virus (van der Schaar et al., 2012). Clinical studies show that enviroxime can relieve symptoms after virus infection, but the therapeutic activity is disappointing (Phillpotts et al., 1981, 1983; Hayden and Gwaltney, 1982; Levandowski et al., 1982; Miller et al., 1985; Higgins et al., 1988). Most of the compounds that directly 


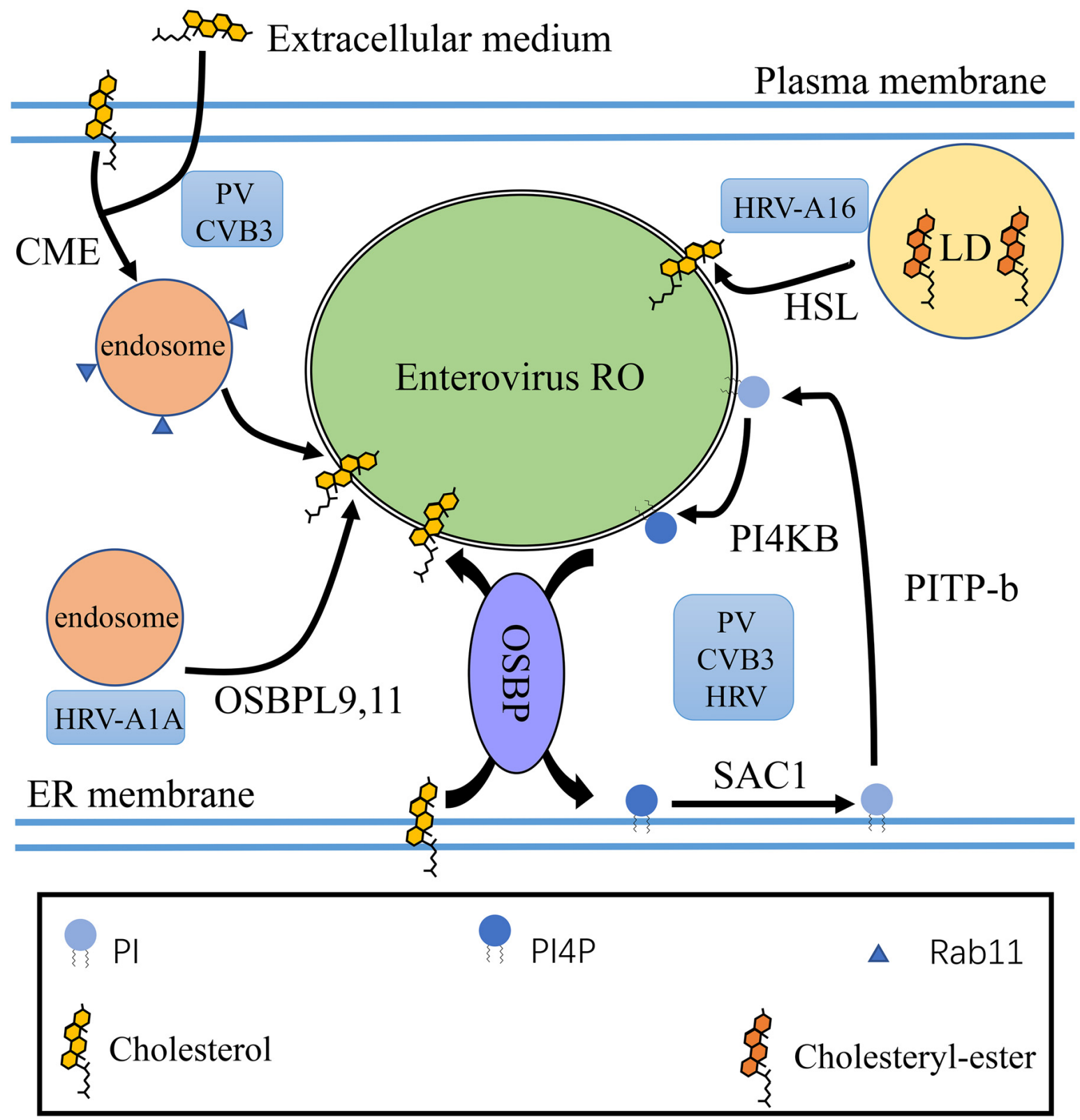

FIGURE 4 | Cholesterol homeostasis of enterovirus ROs. Different enteroviruses utilize multiple mechanisms to enrich cholesterol on ROs. HRV-A16 is dependent on HSL to hydrolyze cholesterol ester stored in LDs. PV and CVB3 activate CME to redistribute cholesterol from the plasma membrane and extracellular medium to ROs and harness Rab11 recycling endosomes to target cholesterol to ROs. Enteroviruses such as PV, CVB3, and HRV can also use OSBP and other host factors driving PI4P-cholesterol countercurrents to increase the level of cholesterol in ROs. OSBP mediates the transfer of PI4P from the ROs to the ER with cholesterol transfer from the ER to the ROs. PI4P is dephosphorylated to PI by Sac1 on the ER membrane. PI is transported to enterovirus ROs from the ER by PITP-b. On the membrane of enterovirus ROs, PI is phosphorylated to PI4P by PI4KB (Roulin et al., 2014; Nchoutmboube et al., 2015).

inhibit PI4KB activity, as well as enviroxime, are known as major enviroxime-like compounds. MDL-860, an atypical enviroximelike compound, is a compound with broad-spectrum antiviral activity. It is one of the few drug candidates that has shown effective antiviral infection in in vivo experiments. MDL-860 treatment causes PI4KB covalent modification and irreversible inactivation (Arita et al., 2017). In addition, another major enviroxime-like compounds, such as pachypodol (Ro 09-0179), oxoglaucine, GW5074, BF-738735, and T-00127-HEV1, can also inhibit PI4KB to hamper the formation of ROs (Arita et al., 2009, 2011, 2015; MacLeod et al., 2013; van der Schaar et al., 2013; Ford Siltz et al., 2014; Bauer et al., 2017; Table 2).

The antiviral function of PI4KB inhibitors has a broad spectrum, as PI4KB acts as a vital part to replicate vRNA. However, some PI4KB inhibitors have shown potential toxicity and side effects (Lamarche et al., 2012; Spickler et al., 2013). 
In addition, enterovirus can resistant the inhibition by PI4KB inhibitors by mutations in the viral 3A protein (van der Schaar et al., 2012; Thibaut et al., 2014; Arita, 2016).

\section{Target OSBP}

Minor enviroxime-like compounds, such as AN-12-H5, T-00127HEV2, 25-HC, and itraconazole (ITZ), are reported to target OSBP to inhibit enterovirus ROs formation (Arita et al., 2013; Strating et al., 2015). ITZ is approved as an antifungal drug, so there are many studies about the in vivo effects (Shim and Liu, 2014). However, we know little about the behavior of others in animals or human. In in vitro tests, TTP-8307 has shown to inhibit lipid diversion by OSBP, so it is a broadspectrum enterovirus inhibitor (Albulescu et al., 2017; Roberts et al., 2019b). OSW-1 is an antiproliferative natural product compound, which targets OSBP and ORP4. OSW-1 potently inhibited the replication of EV71, CVA21, HRV-2, and HRV-14 by targeting OSBP (Albulescu et al., 2015a). Cellular OSBP level reduced after low-dose and short-term treated with OSW-1, with little cytotoxicity. Transiently treated cell with OSW-1 resulted in the persistent OSBP reduction that reduced echovirus 2 and CV-A9 replication (Roberts et al., 2019a,b; Table 2).

\section{Other Targets}

A previous study found that the replication of enteroviruses decreased after BFA treatment. However, a single amino acid mutation in the $2 \mathrm{C}$ and $3 \mathrm{~A}$ regions led to $\mathrm{PV}$ resistance to BFA (Crotty et al., 2004). Golgicide A (GCA) inhibited

TABLE 2 | The inhibitors targeting Enterovirus RO.

\begin{tabular}{|c|c|c|}
\hline Targeted protein & Inhibitor & References \\
\hline \multirow[t]{8}{*}{ PI4KB } & PIK93 & $\begin{array}{l}\text { Knight et al., 2006; Rutaganira et al., } \\
2016\end{array}$ \\
\hline & enviroxime & van der Schaar et al., 2012 \\
\hline & MDL-860 & Arita et al., 2017 \\
\hline & pachypodol & Arita et al., 2015 \\
\hline & oxoglaucine & Arita et al., 2015 \\
\hline & GW5074 & $\begin{array}{l}\text { Arita et al., 2009; Arita et al., 2011; } \\
\text { Ford Siltz et al., } 2014\end{array}$ \\
\hline & BF-738735 & $\begin{array}{l}\text { MacLeod et al., 2013; van der Schaar } \\
\text { et al., } 2013\end{array}$ \\
\hline & T-00127-HEV1 & Arita et al., 2011; MacLeod et al., 2013 \\
\hline \multirow[t]{6}{*}{ OSBP } & AN-12-H5 & Arita et al., 2013 \\
\hline & T-00127-HEV2 & Arita et al., 2013 \\
\hline & $25-\mathrm{HC}$ & Arita et al., 2013 \\
\hline & $\mathrm{ITZ}$ & Strating et al., 2015 \\
\hline & ТТР-8307 & $\begin{array}{l}\text { Albulescu et al., 2017; Roberts et al., } \\
\text { 2019b }\end{array}$ \\
\hline & OSW-1 & $\begin{array}{l}\text { Albulescu et al., 2015a; Roberts et al., } \\
\text { 2019a,b }\end{array}$ \\
\hline COPI & BFA & Crotty et al., 2004 \\
\hline GBF1 & GCA & van der Linden et al., 2010 \\
\hline 2C (viral protein) & $\mathrm{GnHCl}$ & Laufman et al., 2019 \\
\hline ATGL & Atglistatin & Laufman et al., 2019 \\
\hline $\mathrm{HSL}$ & CAY10499 & Laufman et al., 2019 \\
\hline / & NITD008 & Deng et al., 2014 \\
\hline
\end{tabular}

the replication of CVB3 by targeting GBF1 (van der Linden et al., 2010). Guanidine hydrochloride $(\mathrm{GnHCl})$ reduced the MCSs between LDs and ROs by inhibiting the 2C protein of PV to disrupt the biogenesis of ROs. Atglistatin, an ATGL inhibitor, caused kinetic delay of PV infectious particles production. And CAY10499, an inhibitor target HSL, had an effect on PV replication (Laufman et al., 2019). The adenosine analog NITD008 also showed effective inhibition to EV71 (Deng et al., 2014; Table 2).

\section{CONCLUSION}

Researches on enterovirus ROs give us a more comprehensive and in-depth understanding of the enterovirus life cycle. In this review, we summarized the current knowledge of enterovirus ROs, including their function, morphology, biogenesis, and generation mechanism. Enteroviruses share significantly conserved mechanisms to build ROs. The proteins involved in the secretory pathway, the autophagy pathway, and lipid metabolism are all vital for ROs formation. We have found many host factors related to ROs, but several other host proteins that have been proved to play a role in enterovirus replication are often poorly understood. More researches are needed to illuminate how the virus hijacks host factors to initiate the reorganization of the membrane and maintain such an unstable membrane. The current researches on the role of lipids in the formation of ROs are focused on PI4P, and study on other lipids is poor. The function of other lipids remains to be studied. In addition, there are more studies needed to be done to better comprehend the role of ROs in enterovirus life cycle, especially regarding how viruses utilize ROs compartments to consort different steps, such as replication, assembly, and release to achieve enterovirus efficient replication.

\section{AUTHOR CONTRIBUTIONS}

XL conceived, designed, and wrote the manuscript. MW and AC revised the manuscript. XW, XO, SM, QG, DS, RJ, QY, YW, DZ, XZ, SC, ML, SZ, YL, YY, LZ, BT, LP, and XC helped with the manuscript. All authors read and approved the final manuscript for publication.

\section{FUNDING}

This work was supported by the National Key Research and Development Program of China (2017YFD0500800), the China Agricultural Research System (CARS-42-17), the Sichuan Veterinary Medicine and Drug Innovation Group of China Agricultural Research System (SCCXTD-2020-18), and Integration and Demonstration of Key Technologies for Goose Industrial Chain in Sichuan Province (2018NZ0005). 


\section{REFERENCES}

Abernathy, E., Mateo, R., Majzoub, K., van Buuren, N., Bird, S. W., Carette, J. E., et al. (2019). Differential and convergent utilization of autophagy components by positive-strand RNA viruses. PLoS Biol. 17:e2006926. doi: 10.1371/journal. pbio. 2006926

Albulescu, L., Bigay, J., Biswas, B., Weber-Boyvat, M., Dorobantu, C. M., Delang, L., et al. (2017). Uncovering oxysterol-binding protein (OSBP) as a target of the anti-enteroviral compound TTP-8307. Antiviral Res. 140, 37-44. doi: 10.1016/j. antiviral.2017.01.008

Albulescu, L., Strating, J. R., Thibaut, H. J., van der Linden, L., Shair, M. D., Neyts, J., et al. (2015a). Broad-range inhibition of enterovirus replication by OSW-1, a natural compound targeting OSBP. Antiviral Res. 117, 110-114. doi: 10.1016/j.antiviral.2015.02.013

Albulescu, L., Wubbolts, R., van Kuppeveld, F. J., and Strating, J. R. (2015b). Cholesterol shuttling is important for RNA replication of coxsackievirus B3 and encephalomyocarditis virus. Cell Microbiol. 17, 1144-1156. doi: 10.1111/cmi. 12425

Alirezaei, M., Flynn, C. T., Wood, M. R., and Whitton, J. L. (2012). Pancreatic acinar cell-specific autophagy disruption reduces coxsackievirus replication and pathogenesis in vivo. Cell Host Microbe 11, 298-305. doi: 10.1016/j.chom.2012. 01.014

Altan-Bonnet, N. (2017). Lipid tales of viral replication and transmission. Trends Cell Biol. 27, 201-213. doi: 10.1016/j.tcb.2016.09.011

Altan-Bonnet, N., and Balla, T. (2012). Phosphatidylinositol 4-kinases: hostages harnessed to build panviral replication platforms. Trends Biochem. Sci. 37, 293-302. doi: 10.1016/j.tibs.2012.03.004

Arita, M. (2014). Phosphatidylinositol-4 kinase III beta and oxysterol-binding protein accumulate unesterified cholesterol on poliovirus-induced membrane structure. Microbiol. Immunol. 58, 239-256. doi: 10.1111/1348-0421.12144

Arita, M. (2016). Mechanism of poliovirus resistance to host phosphatidylinositol4 kinase III beta inhibitor. ACS Infect. Dis. 2, 140-148. doi: 10.1021/acsinfecdis. 5 b00122

Arita, M. (2019). Essential domains of phosphatidylinositol-4 kinase III beta required for enterovirus replication. Microbiol. Immunol. 63, 285-288. doi: 10.1111/1348-0421.12718

Arita, M., Dobrikov, G., Purstinger, G., and Galabov, A. S. (2017). Allosteric regulation of phosphatidylinositol 4-kinase III beta by an antipicornavirus compound MDL-860. ACS Infect. Dis. 3, 585-594. doi: 10.1021/acsinfecdis. $7 \mathrm{~b} 00053$

Arita, M., Kojima, H., Nagano, T., Okabe, T., Wakita, T., and Shimizu, H. (2011). Phosphatidylinositol 4-kinase III beta is a target of enviroxime-like compounds for antipoliovirus activity. J. Virol. 85, 2364-2372. doi: 10.1128/jvi.02249-10

Arita, M., Kojima, H., Nagano, T., Okabe, T., Wakita, T., and Shimizu, H. (2013). Oxysterol-binding protein family $\mathrm{I}$ is the target of minor enviroxime-like compounds. J. Virol. 87, 4252-4260. doi: 10.1128/jvi.03546-12

Arita, M., Philipov, S., and Galabov, A. S. (2015). Phosphatidylinositol 4-kinase III beta is the target of oxoglaucine and pachypodol (Ro 09-0179) for their antipoliovirus activities, and is located at upstream of the target step of brefeldin A. Microbiol. Immunol. 59, 338-347. doi: 10.1111/1348-0421.12261

Arita, M., Wakita, T., and Shimizu, H. (2009). Cellular kinase inhibitors that suppress enterovirus replication have a conserved target in viral protein $3 \mathrm{~A}$ similar to that of enviroxime. J. General Virol. 90, 1869-1879. doi: 10.1099/vir. 0.012096-0

Banerjee, S., Aponte-Diaz, D., Yeager, C., Sharma, S. D., Ning, G., Oh, H. S., et al. (2018). Hijacking of multiple phospholipid biosynthetic pathways and induction of membrane biogenesis by a picornaviral 3CD protein. PLoS Pathog. 14:e1007086. doi: 10.1371/journal.ppat.1007086

Bauer, L., Lyoo, H., van der Schaar, H. M., Strating, J. R., and van Kuppeveld, F. J. (2017). Direct-acting antivirals and host-targeting strategies to combat enterovirus infections. Curr. Opin. Virol. 24, 1-8. doi: 10.1016/j.coviro.2017.03. 009

Beller, M., Sztalryd, C., Southall, N., Bell, M., Jackle, H., Auld, D. S., et al. (2008). COPI complex is a regulator of lipid homeostasis. PLoS Biol. 6:e292. doi: 10 . 1371/journal.pbio.0060292

Belov, G. A. (2014). Modulation of lipid synthesis and trafficking pathways by picornaviruses. Curr. Opin. Virol. 9, 19-23. doi: 10.1016/j.coviro.2014.08.007

Belov, G. A., Altan-Bonnet, N., Kovtunovych, G., Jackson, C. L., LippincottSchwartz, J., and Ehrenfeld, E. (2007a). Hijacking components of the cellular secretory pathway for replication of poliovirus RNA. J. Virol. 81, 558-567. doi: 10.1128/jvi.01820-06

Belov, G. A., Habbersett, C., Franco, D., and Ehrenfeld, E. (2007b). Activation of cellular Arf GTPases by poliovirus protein 3CD correlates with virus replication. J. Virol. 81, 9259-9267. doi: 10.1128/jvi.00840-07

Belov, G. A., Nair, V., Hansen, B. T., Hoyt, F. H., Fischer, E. R., and Ehrenfeld, E. (2012). Complex dynamic development of poliovirus membranous replication complexes. J. Virol. 86, 302-312. doi: 10.1128/jvi.05937-11

Belov, G. A., and van Kuppeveld, F. J. (2012). (+)RNA viruses rewire cellular pathways to build replication organelles. Curr. Opin. Virol. 2, 740-747. doi: 10.1016/j.coviro.2012.09.006

Belov, G. A., and van Kuppeveld, F. J. M. (2019). Lipid droplets grease enterovirus replication. Cell Host Microbe 26, 149-151. doi: 10.1016/j.chom.2019.07.017

Bienz, K., Egger, D., Pfister, T., and Troxler, M. (1992). Structural and functional characterization of the poliovirus replication complex. J. Virol. 66, 2740-2747. doi: 10.1128/jvi.66.5.2740-2747.1992

Bienz, K., Egger, D., Rasser, Y., and Bossart, W. (1980). Kinetics and location of poliovirus macromolecular synthesis in correlation to virus-induced cytopathology. Virology 100, 390-399. doi: 10.1016/0042-6822(80)90530-9

Blanchard, E., and Roingeard, P. (2015). Virus-induced double-membrane vesicles. Cell Microbiol. 17, 45-50. doi: $10.1111 / \mathrm{cmi} .12372$

Burke, J. E. (2018). Structural basis for regulation of phosphoinositide kinases and their involvement in human disease. Mol. Cell 71, 653-673. doi: 10.1016/ j.molcel.2018.08.005

Cao, Q., Cheng, A., and Wang, M. (2012). Characteristics and function of 3D gene and its encoding protein in picornavirus. Rev. Med. Microbiol. 23, 18-22. doi: 10.1097/MRM.0b013e328352afee

Chalupska, D., Rozycki, B., Klima, M., and Boura, E. (2019). Structural insights into acyl-coenzyme A binding domain containing 3 (ACBD3) protein hijacking by picornaviruses. Protein Sci. 28, 2073-2079. doi: 10.1002/pro.3738

Chen, Y. H., Du, W., Hagemeijer, M. C., Takvorian, P. M., Pau, C., Cali, A., et al. (2015). Phosphatidylserine vesicles enable efficient en bloc transmission of enteroviruses. Cell 160, 619-630. doi: 10.1016/j.cell.2015.01.032

Chiramel, A. I., Brady, N. R., and Bartenschlager, R. (2013). Divergent roles of autophagy in virus infection. Cells 2, 83-104. doi: 10.3390/cells2010083

Corona, A. K., Saulsbery, H. M., Corona Velazquez, A. F., and Jackson, W. T. (2018). Enteroviruses remodel autophagic trafficking through regulation of host SNARE proteins to promote virus replication and cell exit. Cell Rep. 22, 3304-3314. doi: 10.1016/j.celrep.2018.03.003

Crotty, S., Saleh, M. C., Gitlin, L., Beske, O., and Andino, R. (2004). The poliovirus replication machinery can escape inhibition by an antiviral drug that targets a host cell protein. J. Virol. 78, 3378-3386. doi: 10.1128/jvi.78.7.3378-3386.2004

De Craene, J. O., Bertazzi, D. L., Bar, S., and Friant, S. (2017). Phosphoinositides, major actors in membrane trafficking and lipid signaling pathways. Int. J. Mol. Sci. 18:634. doi: 10.3390/ijms18030634

Delang, L., Paeshuyse, J., and Neyts, J. (2012). The role of phosphatidylinositol 4kinases and phosphatidylinositol 4-phosphate during viral replication. Biochem. Pharmacol. 84, 1400-1408. doi: 10.1016/j.bcp.2012.07.034

Delorme-Axford, E., Morosky, S., Bomberger, J., Stolz, D. B., Jackson, W. T., and Coyne, C. B. (2014). BPIFB3 regulates autophagy and coxsackievirus B replication through a noncanonical pathway independent of the core initiation machinery. mBio 5:e02147.

den Boon, J. A., and Ahlquist, P. (2010). Organelle-like membrane compartmentalization of positive-strand RNA virus replication factories. Annu. Rev. Microbiol. 64, 241-256. doi: 10.1146/annurev.micro.112408.134012

Deng, C. L., Yeo, H., Ye, H. Q., Liu, S. Q., Shang, B. D., Gong, P., et al. (2014). Inhibition of enterovirus 71 by adenosine analog NITD008. J. Virol. 88, 1191511923. doi: 10.1128/jvi.01207-14

Dornan, G. L., McPhail, J. A., and Burke, J. E. (2016). Type III phosphatidylinositol 4 kinases: structure, function, regulation, signalling and involvement in disease. Biochem. Soc. Trans. 44, 260-266. doi: 10.1042/bst20150219

Dorobantu, C. M., Ford-Siltz, L. A., Sittig, S. P., Lanke, K. H., Belov, G. A., van Kuppeveld, F. J., et al. (2015). GBF1- and ACBD3-independent recruitment of PI4KIIIbeta to replication sites by rhinovirus 3A proteins. J. Virol. 89, 1913-1918. doi: 10.1128/jvi.02830-14

Dorobantu, C. M., van der Schaar, H. M., Ford, L. A., Strating, J. R., Ulferts, R., Fang, Y., et al. (2014). Recruitment of PI4KIIIbeta to coxsackievirus B3 replication organelles is independent of ACBD3, GBF1, and Arf1. J. Virol 88, 2725-2736. doi: 10.1128/jvi.03650-13 
Egger, D., Pasamontes, L., Bolten, R., Boyko, V., and Bienz, K. (1996). Reversible dissociation of the poliovirus replication complex: functions and interactions of its components in viral RNA synthesis. J. Virol. 70, 8675-8683. doi: 10.1128/jvi. 70.12.8675-8683.1996

Ertel, K. J., Benefield, D., Castano-Diez, D., Pennington, J. G., Horswill, M., den Boon, J. A., et al. (2017). Cryo-electron tomography reveals novel features of a viral RNA replication compartment. Elife 6:e25940. doi: 10.7554/eLife.25940

Ford Siltz, L. A., Viktorova, E. G., Zhang, B., Kouiavskaia, D., Dragunsky, E., Chumakov, K., et al. (2014). New small-molecule inhibitors effectively blocking picornavirus replication. J. Virol. 88, 11091-11107. doi: 10.1128/jvi.01877-14

Gazina, E. V., Mackenzie, J. M., Gorrell, R. J., and Anderson, D. A. (2002). Differential requirements for COPI coats in formation of replication complexes among three genera of Picornaviridae. J. Virol. 76, 11113-11122. doi: 10.1128/ jvi.76.21.11113-11122.2002

Greninger, A. L., Knudsen, G. M., Betegon, M., Burlingame, A. L., and Derisi, J. L. (2012). The $3 \mathrm{~A}$ protein from multiple picornaviruses utilizes the golgi adaptor protein ACBD3 to recruit PI4KIIIbeta. J. Virol. 86, 3605-3616. doi: 10.1128/jvi.06778-11

Guinea, R., and Carrasco, L. (1990). Phospholipid biosynthesis and poliovirus genome replication, two coupled phenomena. Embo J. 9, 2011-2016. doi: 10 . 1002/j.1460-2075.1990.tb08329.x

Hayden, F. G., and Gwaltney, J. M. (1982). Prophylactic activity of intranasal enviroxime against experimentally induced rhinovirus type 39 infection. Antimicrob. Agents Chemother. 21, 892-897. doi: 10.1128/aac.21.6.892

Higgins, P. G., Barrow, G. I., al-Nakib, W., Tyrrell, D. A., DeLong, D. C., and Lenox-Smith, I. (1988). Failure to demonstrate synergy between interferonalpha and a synthetic antiviral, enviroxime, in rhinovirus infections in volunteers. Antiviral Res. 10, 141-149. doi: 10.1016/0166-3542(88)90022-8

Horova, V., Lyoo, H., Rozycki, B., Chalupska, D., Smola, M., Humpolickova, J., et al. (2019). Convergent evolution in the mechanisms of ACBD3 recruitment to picornavirus replication sites. PLoS Pathog. 15:e1007962. doi: 10.1371/journal. ppat. 1007962

Hsu, N. Y., Ilnytska, O., Belov, G., Santiana, M., Chen, Y. H., Takvorian, P. M., et al. (2010). Viral reorganization of the secretory pathway generates distinct organelles for RNA replication. Cell 141, 799-811. doi: 10.1016/j.cell.2010.03. 050

Huang, P. N., Jheng, J. R., Arnold, J. J., Wang, J. R., Cameron, C. E., and Shih, S. R. (2017). UGGT1 enhances enterovirus 71 pathogenicity by promoting viral RNA synthesis and viral replication. PLoS Pathog. 13:e1006375. doi: 10.1371/journal. ppat. 1006375

Ikonen, E. (2008). Cellular cholesterol trafficking and compartmentalization. Nat. Rev. Mol. Cell Biol. 9, 125-138. doi: 10.1038/nrm2336

Ikonen, E. (2018). Mechanisms of cellular cholesterol compartmentalization: recent insights. Curr. Opin Cell. Biol. 53, 77-83. doi: 10.1016/j.ceb.2018.06.002

Ilnytska, O., Santiana, M., Hsu, N. Y., Du, W. L., Chen, Y. H., Viktorova, E. G., et al. (2013). Enteroviruses harness the cellular endocytic machinery to remodel the host cell cholesterol landscape for effective viral replication. Cell Host Microbe 14, 281-293. doi: 10.1016/j.chom.2013.08.002

Irurzun, A., Perez, L., and Carrasco, L. (1992). Involvement of membrane traffic in the replication of poliovirus genomes: effects of brefeldin A. Virology 191, 166-175. doi: 10.1016/0042-6822(92)90178-r

Jiang, P., Liu, Y., Ma, H. C., Paul, A. V., and Wimmer, E. (2014). Picornavirus morphogenesis. Microbiol. Mol. Biol. Rev. 78, 418-437. doi: 10.1128/mmbr. 00012-14

Kallman, F., Williams, R. C., Dulbecco, R., and Vogt, M. (1958). Fine structure of changes produced in cultured cells sampled at specified intervals during a single growth cycle of polio virus. J. Biophys. Biochem. Cytol. 4, 301-308. doi: $10.1083 /$ jcb.4.3.301

Kirkegaard, K., and Jackson, W. T. (2005). Topology of double-membraned vesicles and the opportunity for non-lytic release of cytoplasm. Autophagy 1, 182-184. doi: 10.4161/auto.1.3.2065

Klein, K. A., and Jackson, W. T. (2011). Human rhinovirus 2 induces the autophagic pathway and replicates more efficiently in autophagic cells. J. Virol. 85, 9651-9654. doi: 10.1128/jvi.00316-11

Klima, M., Toth, D. J., Hexnerova, R., Baumlova, A., Chalupska, D., Tykvart, J., et al. (2016). Structural insights and in vitro reconstitution of membrane targeting and activation of human PI4KB by the ACBD3 protein. Sci. Rep. 6:23641. doi: $10.1038 /$ srep23641
Knight, Z. A., Gonzalez, B., Feldman, M. E., Zunder, E. R., Goldenberg, D. D., Williams, O., et al. (2006). A pharmacological map of the PI3-K family defines a role for p110alpha in insulin signaling. Cell 125, 733-747. doi: 10.1016/j.cell. 2006.03.035

Knoops, K., Barcena, M., Limpens, R. W., Koster, A. J., Mommaas, A. M., and Snijder, E. J. (2012). Ultrastructural characterization of arterivirus replication structures: reshaping the endoplasmic reticulum to accommodate viral RNA synthesis. J. Virol. 86, 2474-2487. doi: 10.1128/jvi.06677-11

Knoops, K., Kikkert, M., Worm, S. H., Zevenhoven-Dobbe, J. C., van der Meer, Y., Koster, A. J., et al. (2008). SARS-coronavirus replication is supported by a reticulovesicular network of modified endoplasmic reticulum. PLoS Biol. 6:e226. doi: 10.1371/journal.pbio.0060226

Lai, J. K., Sam, I. C., and Chan, Y. F. (2016). The autophagic machinery in enterovirus infection. Viruses 8:32. doi: 10.3390/v8020032

Lai, J. K. F., Sam, I. C., Verlhac, P., Baguet, J., Eskelinen, E. L., Faure, M., et al. (2017). 2BC non-structural protein of enterovirus A71 interacts with SNARE proteins to trigger autolysosome formation. Viruses 9:169. doi: 10.3390/ v9070169

Lamarche, M. J., Borawski, J., Bose, A., Capacci-Daniel, C., Colvin, R., Dennehy, M., et al. (2012). Anti-hepatitis C virus activity and toxicity of type III phosphatidylinositol-4-kinase beta inhibitors. Antimicrob. Agents Chemother. 56, 5149-5156. doi: 10.1128/aac.00946- 12

Lanke, K. H., van der Schaar, H. M., Belov, G. A., Feng, Q., Duijsings, D., Jackson, C. L., et al. (2009). GBF1, a guanine nucleotide exchange factor for Arf, is crucial for coxsackievirus B3 RNA replication. J. Virol. 83, 11940-11949. doi: 10.1128/jvi.01244-09

Laufman, O., Perrino, J., and Andino, R. (2019). Viral generated inter-organelle contacts redirect lipid flux for genome replication. Cell 178, 275-289.e216. doi: 10.1016/j.cell.2019.05.030

Lee, J. Y., Cortese, M., Haselmann, U., Tabata, K., Romero-Brey, I., Funaya, C., et al. (2019). Spatiotemporal coupling of the hepatitis $C$ virus replication cycle by creating a lipid droplet- proximal membranous replication compartment. Cell Rep. 27, 3602-3617.e5. doi: 10.1016/j.celrep.2019.05.063

Lee, M. C., Miller, E. A., Goldberg, J., Orci, L., and Schekman, R. (2004). Bidirectional protein transport between the ER and Golgi. Annu. Rev. Cell Dev. Biol. 20, 87-123. doi: 10.1146/annurev.cellbio.20.010403.105307

Lei, X., Xiao, X., Zhang, Z., Ma, Y., Qi, J., Wu, C., et al. (2017). The golgi protein ACBD3 facilitates enterovirus 71 replication by interacting with 3 A. Sci. Rep. 7:44592. doi: 10.1038/srep44592

Levandowski, R. A., Pachucki, C. T., Rubenis, M., and Jackson, G. G. (1982). Topical enviroxime against rhinovirus infection. Antimicrob. Agents Chemother. 22, 1004-1007. doi: 10.1128/aac.22.6. 1004

Limpens, R. W., van der Schaar, H. M., Kumar, D., Koster, A. J., Snijder, E. J., van Kuppeveld, F. J., et al. (2011). The transformation of enterovirus replication structures: a three-dimensional study of single- and doublemembrane compartments. mBio 2:e166-11.

Luo, J., Yang, H., and Song, B. L. (2020). Mechanisms and regulation of cholesterol homeostasis. Nat. Rev. Mol. Cell Biol. 21, 225-245. doi: 10.1038/s41580-0190190-7

Lyoo, H., van der Schaar, H. M., Dorobantu, C. M., Rabouw, H. H., Strating, J., and van Kuppeveld, F. J. M. (2019). ACBD3 is an essential pan-enterovirus host factor that mediates the interaction between viral $3 \mathrm{~A}$ protein and cellular protein PI4KB. mBio 10:e2742-18.

MacLeod, A. M., Mitchell, D. R., Palmer, N. J., Van de Poel, H., Conrath, K., Andrews, M., et al. (2013). Identification of a series of compounds with potent antiviral activity for the treatment of enterovirus infections. ACS Med. Chem. Lett. 4, 585-589. doi: 10.1021/ml400095m

Maynell, L. A., Kirkegaard, K., and Klymkowsky, M. W. (1992). Inhibition of poliovirus RNA synthesis by brefeldin A. J. Virol. 66, 1985-1994. doi: 10.1128/ jvi.66.4.1985-1994.1992

McCloskey, M. A., and Poo, M. M. (1986). Rates of membrane-associated reactions: reduction of dimensionality revisited. J. Cell Biol. 102, 88-96. doi: 10.1083/jcb. 102.1.88

McPhail, J. A., Lyoo, H., Pemberton, J. G., Hoffmann, R. M., van Elst, W., Strating, J. R., et al. (2020). Characterization of the c10orf76-PI4KB complex and its necessity for Golgi PI4P levels and enterovirus replication. EMBO Rep. 21:e48441. doi: 10.15252/embr.201948441 
Melia, C. E., Peddie, C. J., de Jong, A. W. M., Snijder, E. J., Collinson, L. M., Koster, A. J., et al. (2019). Origins of enterovirus replication organelles established by whole-cell electron microscopy. mBio 10:e951-19.

Melia, C. E., van der Schaar, H. M., de Jong, A. W. M., Lyoo, H. R., Snijder, E. J., Koster, A. J., et al. (2018). The Origin, Dynamic Morphology, and PI4PIndependent Formation of Encephalomyocarditis Virus Replication Organelles. mBio 9:e420-18.

Melia, C. E., van der Schaar, H. M., Lyoo, H., Limpens, R., Feng, Q., Wahedi, M., et al. (2017). Escaping host factor PI4KB inhibition: enterovirus genomic RNA replication in the absence of replication organelles. Cell Rep. 21, 587-599. doi: 10.1016/j.celrep.2017.09.068

Mesmin, B., Bigay, J., Moser, von Filseck, J., Lacas-Gervais, S., Drin, G., et al. (2013). A four-step cycle driven by $\mathrm{PI}(4) \mathrm{P}$ hydrolysis directs sterol/PI(4)P exchange by the ER-Golgi tether OSBP. Cell 155, 830-843. doi: 10.1016/j.cell.2013.09.056

Mesmin, B., Bigay, J., Polidori, J., Jamecna, D., Lacas-Gervais, S., and Antonny, B. (2017). Sterol transfer, PI4P consumption, and control of membrane lipid order by endogenous OSBP. EMBO J. 36, 3156-3174. doi: 10.15252/embj.201796687

Miller, F. D., Monto, A. S., DeLong, D. C., Exelby, A., Bryan, E. R., and Srivastava, S. (1985). Controlled trial of enviroxime against natural rhinovirus infections in a community. Antimicrob. Agents Chemother. 27, 102-106. doi: 10.1128/aac.27. 1.102

Mohamud, Y., and Luo, H. (2019). The intertwined life cycles of enterovirus and autophagy. Virulence 10, 470-480. doi: 10.1080/21505594.2018.1551010

Mohamud, Y., Shi, J., Qu, J., Poon, T., Xue, Y. C., Deng, H., et al. (2018). Enteroviral infection inhibits autophagic flux via disruption of the SNARE complex to enhance viral replication. Cell Rep. 22, 3292-3303. doi: 10.1016/j.celrep.2018. 02.090

Molla, A., Paul, A. V., and Wimmer, E. (1993). Effects of temperature and lipophilic agents on poliovirus formation and RNA synthesis in a cell-free system. J. Virol. 67, 5932-5938. doi: 10.1128/jvi.67.10.5932-5938.1993

Mousnier, A., Swieboda, D., Pinto, A., Guedan, A., Rogers, A. V., Walton, R., et al. (2014). Human rhinovirus 16 causes Golgi apparatus fragmentation without blocking protein secretion. J. Virol. 88, 11671-11685. doi: 10.1128/jvi.01170-14

Nchoutmboube, J., Ford-Siltz, L. A., and Belov, G. A. (2015). Enterovirus replication: go with the (counter)flow. Trends Microbiol. 23, 183-184. doi: 10.1016/j.tim.2015.02.008

Nchoutmboube, J. A., Viktorova, E. G., Scott, A. J., Ford, L. A., Pei, Z., Watkins, P. A., et al. (2013). Increased long chain acyl-Coa synthetase activity and fatty acid import is linked to membrane synthesis for development of picornavirus replication organelles. PLoS Pathog. 9:e1003401. doi: 10.1371/journal.ppat. 1003401

Novoa, R. R., Calderita, G., Arranz, R., Fontana, J., Granzow, H., and Risco, C. (2005). Virus factories: associations of cell organelles for viral replication and morphogenesis. Biol. Cell 97, 147-172. doi: 10.1042/bc20040058

Oh, H. S., Banerjee, S., Aponte-Diaz, D., Sharma, S. D., Aligo, J., Lodeiro, M. F., et al. (2018). Multiple poliovirus-induced organelles suggested by comparison of spatiotemporal dynamics of membranous structures and phosphoinositides. PLoS Pathog. 14:e1007036. doi: 10.1371/journal.ppat.1007036

Owino, C. O., and Chu, J. J. H. (2019). Recent advances on the role of host factors during non-poliovirus enteroviral infections. J. Biomed. Sci. 26:47. doi: 10.1186/s12929-019-0540-y

Paul, D., and Bartenschlager, R. (2013). Architecture and biogenesis of plus-strand RNA virus replication factories. World J. Virol. 2, 32-48. doi: 10.5501/wjv.v2.i2. 32

Payrastre, B., Missy, K., Giuriato, S., Bodin, S., Plantavid, M., and Gratacap, M. (2001). Phosphoinositides: key players in cell signalling, in time and space. Cell Signal 13, 377-387. doi: 10.1016/s0898-6568(01)00158-9

Peersen, O. B. (2017). Picornaviral polymerase structure, function, and fidelity modulation. Virus Res. 234, 4-20. doi: 10.1016/j.virusres.2017.01.026

Phillpotts, R. J., Jones, R. W., Delong, D. C., Reed, S. E., Wallace, J., and Tyrrell, D. A. (1981). The activity of enviroxime against rhinovirus infection in man. Lancet 1, 1342-1344. doi: 10.1016/s0140-6736(81)92520-4

Phillpotts, R. J., Wallace, J., Tyrrell, D. A., and Tagart, V. B. (1983). Therapeutic activity of enviroxime against rhinovirus infection in volunteers. Antimicrob. Agents Chemother. 23, 671-675. doi: 10.1128/aac.23.5.671

Pleet, M. L., Branscome, H., DeMarino, C., Pinto, D. O., Zadeh, M. A., Rodriguez, M., et al. (2018). Autophagy, EVs, and infections: a perfect question for a perfect time. Front. Cell. Infect. Microbiol. 8:362. doi: 10.3389/fcimb.2018.00362
Rassmann, A., Henke, A., Jarasch, N., Lottspeich, F., Saluz, H. P., and Munder, T. (2007). The human fatty acid synthase: a new therapeutic target for coxsackievirus B3-induced diseases? Antiviral Res. 76, 150-158. doi: 10.1016/ j.antiviral.2007.06.011

Ravindran, M. S., Bagchi, P., Cunningham, C. N., and Tsai, B. (2016). Opportunistic intruders: how viruses orchestrate ER functions to infect cells. Nat. Rev. Microbiol. 14, 407-420. doi: 10.1038/nrmicro.2016.60

Richards, A. L., and Jackson, W. T. (2012). Intracellular vesicle acidification promotes maturation of infectious poliovirus particles. PLoS Pathog. 8:e1003046. doi: 10.1371/journal.ppat.1003046

Richards, A. L., Soares-Martins, J. A., Riddell, G. T., and Jackson, W. T. (2014). Generation of unique poliovirus RNA replication organelles. mBio 5:e833-13.

Roberts, B. L., Severance, Z. C., Bensen, R. C., Le, A. T., Kothapalli, N. R., Nunez, J. I., et al. (2019a). Transient compound treatment induces a multigenerational reduction of oxysterol-binding protein (OSBP) levels and prophylactic antiviral activity. ACS Chem. Biol. 14, 276-287. doi: 10.1021/acschembio.8b00984

Roberts, B. L., Severance, Z. C., Bensen, R. C., Le-McClain, A. T., Malinky, C. A., Mettenbrink, E. M., et al. (2019b). Differing activities of oxysterol-binding protein (OSBP) targeting anti-viral compounds. Antiviral Res. 170:104548. doi: 10.1016/j.antiviral.2019.104548

Romero-Brey, I., and Bartenschlager, R. (2014). Membranous replication factories induced by plus-strand RNA viruses. Viruses 6, 2826-2857. doi: 10.3390/ v6072826

Roulin, P. S., Lotzerich, M., Torta, F., Tanner, L. B., van Kuppeveld, F. J., Wenk, M. R., et al. (2014). Rhinovirus uses a phosphatidylinositol 4-phosphate/cholesterol counter-current for the formation of replication compartments at the ER-Golgi interface. Cell Host Microbe 16, 677-690. doi: 10.1016/j.chom.2014.10.003

Roulin, P. S., Murer, L. P., and Greber, U. F. (2018). A single point mutation in the rhinovirus $2 \mathrm{~B}$ protein reduces the requirement for phosphatidylinositol 4-kinase class III beta in viral replication. J. Virol. 92:e1462-18.

Rust, R. C., Landmann, L., Gosert, R., Tang, B. L., Hong, W., Hauri, H. P., et al. (2001). Cellular COPII proteins are involved in production of the vesicles that form the poliovirus replication complex. J. Virol. 75, 9808-9818. doi: 10.1128/ jvi.75.20.9808-9818.2001

Rutaganira, F. U., Fowler, M. L., McPhail, J. A., Gelman, M. A., Nguyen, K., Xiong, A., et al. (2016). Design and structural characterization of potent and selective inhibitors of phosphatidylinositol 4 kinase IIIbeta. J. Med. Chem. 59, 1830-1839. doi: 10.1021/acs.jmedchem.5b01311

Sachse, M., Fernandez, de Castro, I., Tenorio, R., and Risco, C. (2019). The viral replication organelles within cells studied by electron microscopy. Adv. Virus Res. 105, 1-33. doi: 10.1016/bs.aivir.2019.07.005

Sasaki, J., Ishikawa, K., Arita, M., and Taniguchi, K. (2012). ACBD3-mediated recruitment of PI4KB to picornavirus RNA replication sites. EMBO J. 31, 754-766. doi: 10.1038/emboj.2011.429

Sasvari, Z., and Nagy, P. D. (2010). Making of viral replication organelles by remodeling interior membranes. Viruses 2, 2436-2442. doi: 10.3390/v2112436

Shi, Y., He, X., Zhu, G., Tu, H., Liu, Z., Li, W., et al. (2015). Coxsackievirus A16 elicits incomplete autophagy involving the mTOR and ERK pathways. PLoS ONE 10:e0122109. doi: 10.1371/journal.pone.0122109

Shim, J. S., and Liu, J. O. (2014). Recent advances in drug repositioning for the discovery of new anticancer drugs. Int. J. Biol. Sci. 10, 654-663. doi: 10.7150/ ijbs. 9224

Siljamaki, E., Rintanen, N., Kirsi, M., Upla, P., Wang, W., Karjalainen, M., et al. (2013). Cholesterol dependence of collagen and echovirus 1 trafficking along the novel alpha2betal integrin internalization pathway. PLoS ONE 8:e55465. doi: 10.1371/journal.pone.0055465

Smola, M., Horova, V., Boura, E., and Klima, M. (2020). Structural basis for hijacking of the host ACBD3 protein by bovine and porcine enteroviruses and kobuviruses. Arch. Virol. 165, 355-366. doi: 10.1007/s00705-019-04490-9

Spector, A. A., and Yorek, M. A. (1985). Membrane lipid composition and cellular function. J. Lipid Res. 26, 1015-1035.

Spickler, C., Lippens, J., Laberge, M. K., Desmeules, S., Bellavance, E., Garneau, M., et al. (2013). Phosphatidylinositol 4-kinase III beta is essential for replication of human rhinovirus and its inhibition causes a lethal phenotype in vivo. Antimicrob. Agents Chemother. 57, 3358-3368. doi: 10.1128/aac.00303-13

Strating, J. R., van der Linden, L., Albulescu, L., Bigay, J., Arita, M., Delang, L., et al. (2015). Itraconazole inhibits enterovirus replication by targeting the 
oxysterol-binding protein. Cell Rep. 10, 600-615. doi: 10.1016/j.celrep.2014. 12.054

Strating, J. R., van der Schaar, H. M., and van Kuppeveld, F. J. (2013). Cholesterol: $\mathrm{fa}(\mathrm{s}) \mathrm{t}-\mathrm{food}$ for enterovirus genome replication. Trends Microbiol. 21, 560-561. doi: 10.1016/j.tim.2013.09.007

Strating, J. R., and van Kuppeveld, F. J. (2017). Viral rewiring of cellular lipid metabolism to create membranous replication compartments. Curr. Opin. Cell Biol. 47, 24-33. doi: 10.1016/j.ceb.2017.02.005

Sugden, B., Jackson, W. T., Giddings, T. H., Taylor, M. P., Mulinyawe, S., Rabinovitch, M., et al. (2005). Subversion of cellular autophagosomal machinery by RNA viruses. PLoS Biol. 3:e156. doi: 10.1371/journal.pbio. 0030156

Suhy, D. A., Giddings, T. H. Jr., and Kirkegaard, K. (2000). Remodeling the endoplasmic reticulum by poliovirus infection and by individual viral proteins: an autophagy-like origin for virus-induced vesicles. J. Virol. 74, 8953-8965. doi: 10.1128/jvi.74.19.8953-8965.2000

Sun, D., Wen, X., Wang, M., Mao, S., Cheng, A., Yang, X., et al. (2019). Apoptosis and autophagy in picornavirus infection. Front. Microbiol. 10:2032. doi: 10. 3389/fmicb.2019.02032

Tang, W. F., Yang, S. Y., Wu, B. W., Jheng, J. R., Chen, Y. L., Shih, C. H., et al. (2007). Reticulon 3 binds the $2 C$ protein of enterovirus 71 and is required for viral replication. J. Biol. Chem. 282, 5888-5898. doi: 10.1074/jbc.M611145200

Tapparel, C., Siegrist, F., Petty, T. J., and Kaiser, L. (2013). Picornavirus and enterovirus diversity with associated human diseases. Infect. Genet. Evol. 14, 282-293. doi: 10.1016/j.meegid.2012.10.016

Taylor, M. P., and Kirkegaard, K. (2007). Modification of cellular autophagy protein LC3 by poliovirus. J. Virol. 81, 12543-12553. doi: 10.1128/jvi.00755-07

Teoule, F., Brisac, C., Pelletier, I., Vidalain, P. O., Jegouic, S., Mirabelli, C., et al. (2013). The golgi protein ACBD3, an interactor for poliovirus protein $3 \mathrm{~A}$, modulates poliovirus replication. J. Virol. 87, 11031-11046. doi: 10.1128/jvi. 00304-13

Thibaut, H. J., van der Schaar, H. M., Lanke, K. H., Verbeken, E., Andrews, M., Leyssen, P., et al. (2014). Fitness and virulence of a coxsackievirus mutant that can circumnavigate the need for phosphatidylinositol 4-kinase class III beta. J. Virol. 88, 3048-3051. doi: 10.1128/jvi.03177-13

Trahey, M., Oh, H. S., Cameron, C. E., and Hay, J. C. (2012). Poliovirus infection transiently increases COPII vesicle budding. J. Virol. 86, 9675-9682. doi: 10. 1128/jvi.01159- 12

van der Linden, L., van der Schaar, H. M., Lanke, K. H., Neyts, J., and van Kuppeveld, F. J. (2010). Differential effects of the putative GBF1 inhibitors golgicide A and AG1478 on enterovirus replication. J. Virol. 84, 7535-7542. doi: $10.1128 /$ jvi.02684-09

van der Schaar, H. M., Dorobantu, C. M., Albulescu, L., Strating, J., and van Kuppeveld, F. J. M. (2016a). Fat(al) attraction: picornaviruses usurp lipid transfer at membrane contact sites to create replication organelles. Trends Microbiol. 24, 535-546. doi: 10.1016/j.tim.2016.02.017

van der Schaar, H. M., Melia, C. E., van Bruggen, J. A., Strating, J. R., van Geenen, M. E., Koster, A. J., et al. (2016b). Illuminating the sites of enterovirus replication in living cells by using a split-GFP-tagged viral protein. mSphere 1:e104-16.

van der Schaar, H. M., Leyssen, P., Thibaut, H. J., de Palma, A., van der Linden, L., Lanke, K. H., et al. (2013). A novel, broad-spectrum inhibitor of enterovirus replication that targets host cell factor phosphatidylinositol 4-kinase IIIbeta. Antimicrob. Agents Chemother. 57, 4971-4981. doi: 10.1128/aac.01175-13

van der Schaar, H. M., van der Linden, L., Lanke, K. H., Strating, J. R., Purstinger, G., de Vries, E., et al. (2012). Coxsackievirus mutants that can bypass host factor PI4KIIIbeta and the need for high levels of PI4P lipids for replication. Cell Res. 22, 1576-1592. doi: 10.1038/cr.2012.129

van Meer, G., Voelker, D. R., and Feigenson, G. W. (2008). Membrane lipids: where they are and how they behave. Nat. Rev. Mol. Cell Biol. 9, 112-124. doi: $10.1038 / \mathrm{nrm} 2330$

Vance, D. E., Trip, E. M., and Paddon, H. B. (1980). Poliovirus increases phosphatidylcholine biosynthesis in HeLa cells by stimulation of the ratelimiting reaction catalyzed by CTP: phosphocholine cytidylyltransferase. J. Biol. Chem. 255, 1064-1069.

Viaud, J., Mansour, R., Antkowiak, A., Mujalli, A., Valet, C., Chicanne, G., et al. (2016). Phosphoinositides: important lipids in the coordination of cell dynamics. Biochimie 125, 250-258. doi: 10.1016/j.biochi.2015. 09.005
Viktorova, E. G., Gabaglio, S., Meissner, J. M., Lee, E., Moghimi, S., Sztul, E., et al. (2019). A redundant mechanism of recruitment underlies the remarkable plasticity of the requirement of poliovirus replication for the cellular ArfGEF GBF1. J. Virol. 93:e856-19.

Viktorova, E. G., Nchoutmboube, J. A., Ford-Siltz, L. A., Iverson, E., and Belov, G. A. (2018). Phospholipid synthesis fueled by lipid droplets drives the structural development of poliovirus replication organelles. PLoS Pathog. 14:e1007280. doi: 10.1371/journal.ppat.1007280

Voilquin, L., Di Mattia, T., and Alpy, F. (2020). Another hijack! some enteroviruses co-opt the c10orf76/PI4KB complex for their own good. EMBO Rep. 21:e49876. doi: $10.15252 / \mathrm{embr} .201949876$

Wang, J., Du, J., and Jin, Q. (2014). Class I ADP-ribosylation factors are involved in enterovirus 71 replication. PLoS ONE 9:e99768. doi: 10.1371/journal.pone. 0099768

Wang, J., Ptacek, J. B., Kirkegaard, K., and Bullitt, E. (2013). Double-membraned liposomes sculpted by poliovirus 3AB protein. J. Biol. Chem. 288, 27287-27298. doi: 10.1074/jbc.M113.498899

Wang, J., Wu, Z., and Jin, Q. (2012). COPI is required for enterovirus 71 replication. PLoS ONE 7:e38035. doi: 10.1371/journal.pone.0038035

Wen, X., Cheng, A., Wang, M., Jia, R., Zhu, D., Chen, S., et al. (2015). Recent advances from studies on the role of structural proteins in enterovirus infection. Future Microbiol. 10, 1529-1542. doi: 10.2217/fmb.15.62

Wikel, J. H., Paget, C. J., DeLong, D. C., Nelson, J. D., Wu, C. Y., Paschal, J. W., et al. (1980). Synthesis of syn and anti isomers of 6-[[(hydroxyimino)phenyl]methyl]-1-[(1-methylethyl)sulfonyl]-1H-

benzimidazol-2-amine, inhibitors of rhinovirus multiplication. J. Med. Chem. 23, 368-372. doi: 10.1021/jm00178a004

Wilsky, S., Sobotta, K., Wiesener, N., Pilas, J., Althof, N., Munder, T., et al. (2012). Inhibition of fatty acid synthase by amentoflavone reduces coxsackievirus B3 replication. Arch. Virol. 157, 259-269. doi: 10.1007/s00705-011-1164-z

Wolff, G., Melia, C. E., Snijder, E. J., and Barcena, M. (2020). Double-membrane vesicles as platforms for viral replication. Trends Microbiol. doi: 10.1016/j.tim. 2020.05.009 [Epub ahead of print].

Wong, J., Zhang, J., Si, X., Gao, G., Mao, I., McManus, B. M., et al. (2008). Autophagosome supports coxsackievirus B3 replication in host cells. J. Virol. 82, 9143-9153. doi: 10.1128/jvi.00641-08

Wu, H., Zhai, X., Chen, Y., Wang, R., Lin, L., Chen, S., et al. (2016). Protein 2B of coxsackievirus B3 induces autophagy relying on its transmembrane hydrophobic sequences. Viruses 8:131. doi: 10.3390/v8050131

Xiao, X., Lei, X., Zhang, Z., Ma, Y., Qi, J., Wu, C., et al. (2017). Enterovirus 3A facilitates viral replication by promoting phosphatidylinositol 4-kinase IIIbetaACBD3 interaction. J. Virol. 91:e791-17.

Yoon, S. Y., Ha, Y. E., Choi, J. E., Ahn, J., Lee, H., Kweon, H. S., et al. (2008). Coxsackievirus B4 uses autophagy for replication after calpain activation in rat primary neurons. J. Virol. 82, 11976-11978. doi: 10.1128/jvi.01028-08

Yue, X., Qian, Y., Gim, B., and Lee, I. (2019). Acyl-CoA-binding domaincontaining 3 (ACBD3; PAP7; GCP60): a multi-functional membrane domain organizer. Int. J. Mol. Sci. 20:2028. doi: 10.3390/ijms20082028

Zechner, R., Madeo, F., and Kratky, D. (2017). Cytosolic lipolysis and lipophagy: two sides of the same coin. Nat. Rev. Mol. Cell Biol. 18, 671-684. doi: 10.1038/ nrm.2017.76

Zhang, J., Zhang, Z., Chukkapalli, V., Nchoutmboube, J. A., Li, J., Randall, G., et al. (2016). Positive-strand RNA viruses stimulate host phosphatidylcholine synthesis at viral replication sites. Proc. Natl. Acad. Sci. U.S.A. 113, E1064E1073. doi: 10.1073/pnas.1519730113

Zhang, Y., Cao, X., and Li, D. (2015). Architecture of viral replication factories. Oncotarget 6, 30439-30440. doi: 10.18632/oncotarget.5900

Conflict of Interest: The authors declare that the research was conducted in the absence of any commercial or financial relationships that could be construed as a potential conflict of interest.

Copyright (c) 2020 Li, Wang, Cheng, Wen, Ou, Mao, Gao, Sun, Jia, Yang, Wu, Zhu, Zhao, Chen, Liu, Zhang, Liu, Yu, Zhang, Tian, Pan and Chen. This is an open-access article distributed under the terms of the Creative Commons Attribution License (CC BY). The use, distribution or reproduction in other forums is permitted, provided the original author(s) and the copyright owner(s) are credited and that the original publication in this journal is cited, in accordance with accepted academic practice. No use, distribution or reproduction is permitted which does not comply with these terms. 